UNIVERSIDADE DE SÃO PAULO

FACULDADE DE DIREITO

RAFAEL SZMID

Monitores anticorrupção no Direito brasileiro

São Paulo

2020 
RAFAEL SZMID

\section{Monitores anticorrupção no Direito brasileiro}

\section{Versão Original}

Tese apresentada à Faculdade de Direito da Universidade de São Paulo para a obtenção do título de Doutor em Direito.

Área de concentração: Direito Comercial

Orientador: Dr. Newton De Lucca

São Paulo

2020 


\section{RESUMO}

Esta tese envolve o estudo dos monitores corporativos independentes anticorrupção no Brasil. O trabalho analisa o regramento jurídico aplicável ao tema e identifica os desafios jurídicos inerentes à utilização dessa ferramenta de combate à corrupção no contexto de acordos no âmbito administrativo e judicial, bem como a possibilidade de sua imposição de forma unilateral por autoridade governamental. Por ser um instituto importado dos Estados Unidos da América, jurisdição que possui uma tradição de justiça negociada e adversarial (ou acusatória) diversa dos ordenamentos jurídicos que adotam o "Civil Law”, como o brasileiro, a utilização do monitoramento anticorrupção impõe uma série de desafios específicos e exige ajustes para que a sua adoção ocorra de forma lícita e adequada no Brasil. Sugere-se, portanto, que haja a regulação local do tema de forma a atribuir legitimidade à utilização do monitoramento anticorrupção e reduzir a insegurança jurídica que atualmente envolve o assunto. Sem isso, esse mecanismo de expressão do interesse público em casos de corrupção não possuirá a importância e adequação necessárias no Brasil. 


\begin{abstract}
This thesis discusses anti-corruption independent corporate monitors in Brazil. The thesis analyses the legal rules applicable to this issue and identifies the legal requirements and specific challenges in connection with the utilization of this mechanism to fight corruption in both administrative and judicial settlements, as well as the possibility of its adoption by a unilateral decision from a public authority. Given the fact that the utilization of anticorruption monitors was imported from the U.S. legal system as part of a negotiated justice and adversarial system, the use of anticorruption corporate monitoring imposes several specific challenges and requires adjustments in order to be used in accordance with Brazil's legal system and in an effective way. The author suggests the enactment of a specific regulation of the anti-corruption independent corporate monitors to increase its legitimacy and reduces the legal uncertainty currently involving this matter. Without this adjustments, this mechanism that manifests the public interest in corruption investigations will lack the required importance and adequacy in Brazil.
\end{abstract}




\section{PRINCIPAIS SIGLAS}

AGU

CADE

$\mathrm{CGU}$

$\mathrm{CNJ}$

CNMP

CPC

CVM

DOJ

DPA

EUA

FBI

FCPA

MP

MPF

MPF

OCDE

ONU

$\mathrm{PF}$

PREVIC

SEC

SFO

TCU
Advocacia-Geral da União

Conselho Administrativo de Defesa Econômica

Controladoria Geral da União

Conselho Nacional de Justiça

Conselho Nacional do Ministério Público

Código de Processo Civil

Comissão de Valores Mobiliário

U.S. Department of Justice

Deferred Prosecution Agreement

Estados Unidos da América

Federal Bureau of Investigation

Foreign Corrupt Practices Act

Ministério Público Estadual e Federal

Ministério Público Estadual

Ministério Público Federal

Organização para a Cooperação e o Desenvolvimento

Econômico

Organização das Nações Unidas

Polícia Federal

Superintendência Nacional de Previdência Complementar Securities and Exchange Commission

Serious Fraud Office

Tribunal de Contas da União 


\section{SUMÁRIO:}

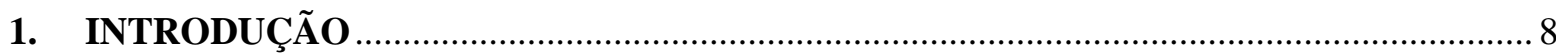

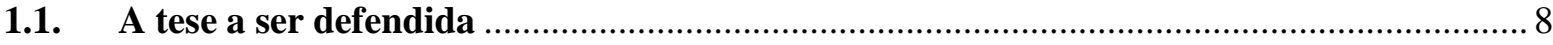

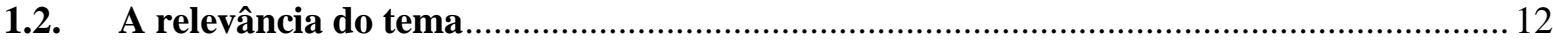

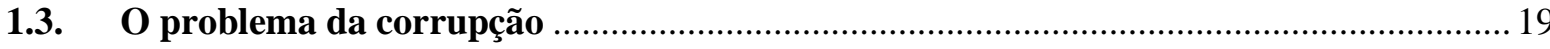

2. O PLEA BARGAINING ESTADUNIDENSE E TRANSPLANTES JURÍDICOS ............25

3. AJUSTES PÓS TRANSPLANTES JURÍDICOS: CONSIDERAÇÕES GERAIS E

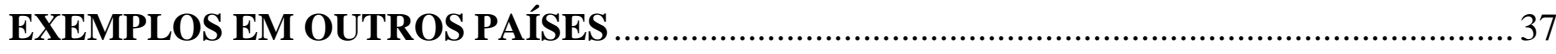

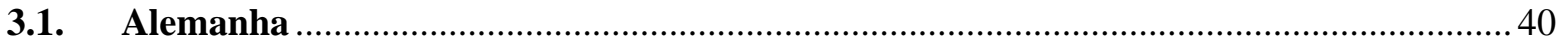

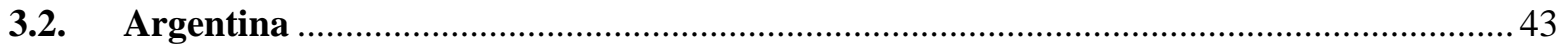

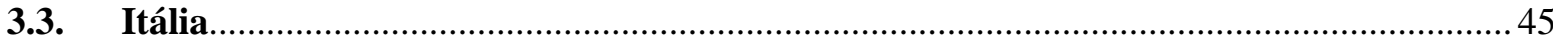

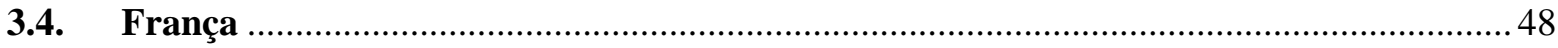

4. ABSORÇÃO PELO BRASIL DE ASPECTOS DO SISTEMA ADVERSARIAL ...............51

5. O MODELO FCPA/OCDE E A SUA PROPAGAÇÃO PELO MUNDO............................. 69

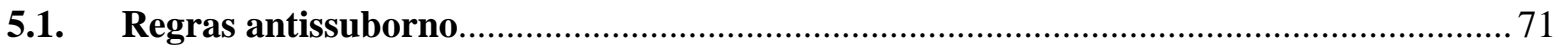

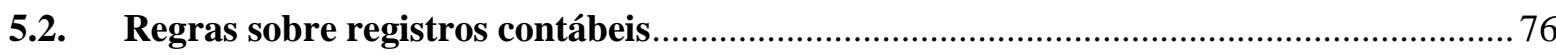

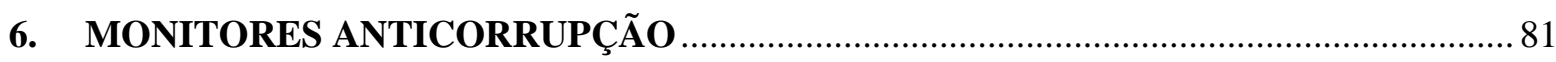

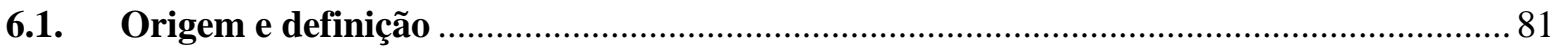

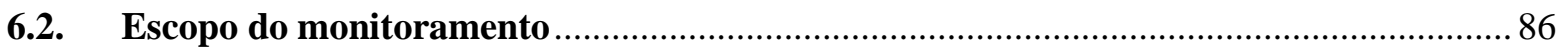

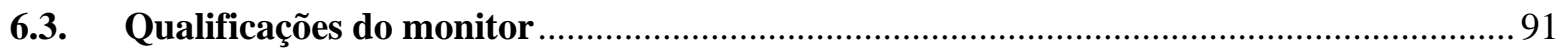

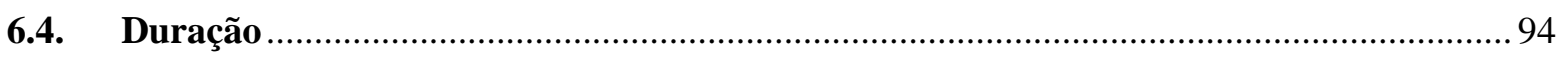

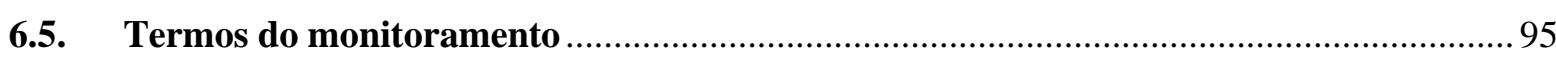

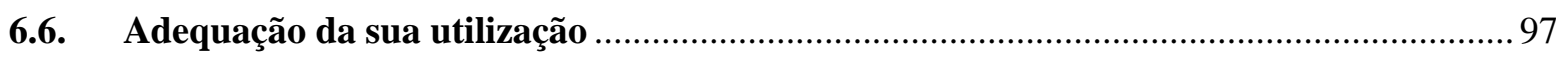

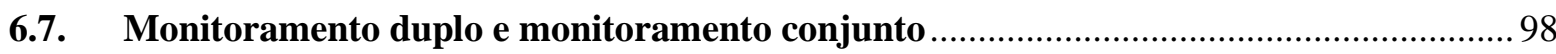

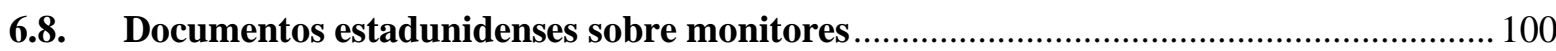

6.9. Casos envolvendo o monitoramento de empresas brasileiras ........................................... 106

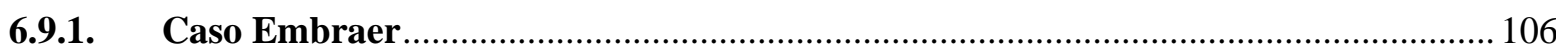

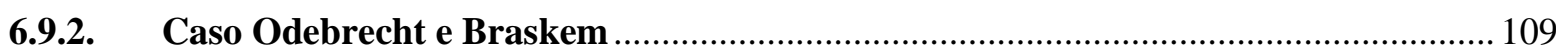

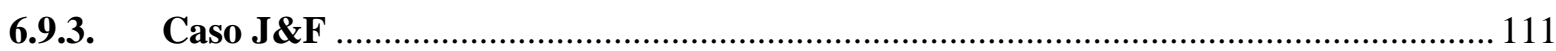

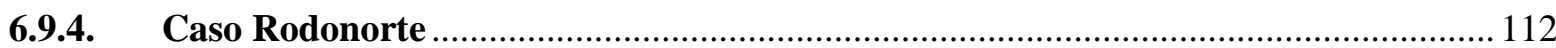

7. REGRAMENTO SOBRE A UTILIZAÇÃO DE MONITORES NO BRASIL ................... 114

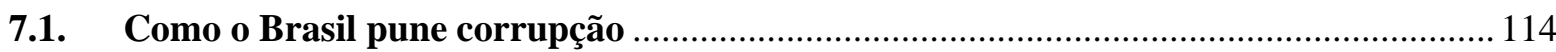

7.2. Regramento a ser utilizado para a nomeação de monitores.......................................... 129

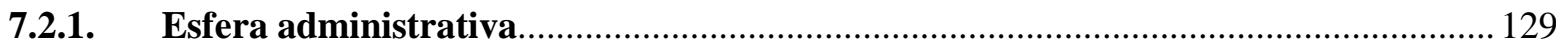


7.2.2. Esfera judicial.

8. PONTOS CRÍTICOS SOBRE A UTILIZAÇÃO DE MONITORES NO BRASIL 161

8.1. Indisponibilidade da utilização de um monitor em determinados casos 161

8.2. Aspectos normativos e culturais 163

8.3. Alegação de ilegalidade da "justiça negociada" 164

8.4. Impunidade 167

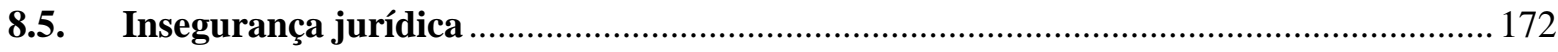

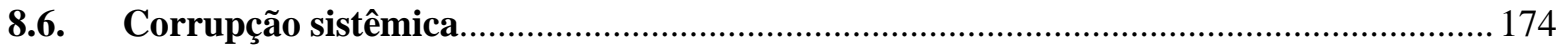

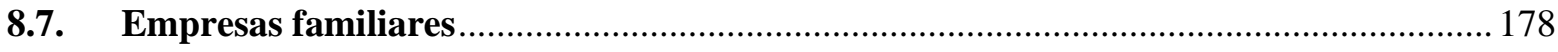

8.8. Participação do Estado na economia ............................................................................. 179

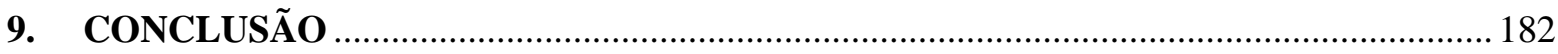

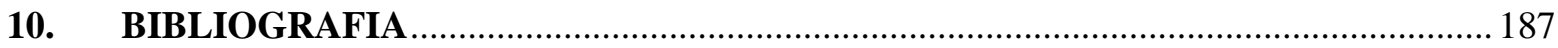

11. ANEXO I - DISPOSITIVOS USADOS COMO BASE JURÍDICA PARA O ACORDO

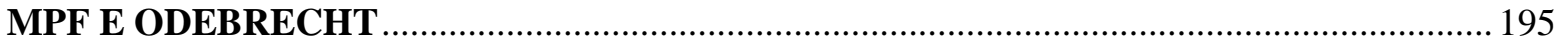




\section{INTRODUÇÃO}

\subsection{A tese a ser defendida}

Monitores corporativos independentes anticorrupção ("Monitor" ou, no plural, "Monitores") ${ }^{1}$ são ferramentas assecuratórias de cumprimento de obrigações acordadas ou exigidas por autoridades públicas no contexto de grandes casos de corrupção, em particular aquelas obrigações relacionadas à adesão e introdução de mecanismos efetivos de integridade corporativa.

O uso de Monitores é um instrumento tradicional do sistema jurídico estadunidense, em particular nos casos envolvendo corrupção transnacional, que foi importado para uma série de jurisdições, incluindo para o Brasil. Por conseguinte, para que se torne uma ferramenta lícita, adequada e eficiente de redução da corrupção no ambiente corporativo no Brasil, devese promover a sua compatibilização ao ordenamento jurídico pátrio e adequação às demais particularidades da realidade brasileira (i.e., econômica, social, política, cultural, etc. $)^{2}$.

Nessa esteira, a tese ora proposta busca defender que, do ponto de vista jurídico, disciplinar a utilização de Monitores no Brasil, com a inclusão de dispositivos específicos no ordenamento jurídico pátrio, é a forma mais adequada de se regular o tema. Para atingir os objetivos almejados, tal regulamentação deve incluir elementos básicos, como a definição de critérios materiais e temporais para o uso de um Monitor, o processo de escolha, nomeação e

\footnotetext{
1 Monitores podem receber diferentes designações, de modo que, para os propósitos desta tese, Monitores independentes, Monitores de conformidade, Monitores anticorrupção e variações destes termos devem ser compreendidos de forma indistinta ao longo deste trabalho. Sobre o tema: "When searching our Public Resource Center, please keep in mind that Corporate Monitors are referred to by many names, which we have captured in accordance with that used in the Agreements within our repository, including, but not limited to: Independent Corporate Monitor, Compliance Monitor, Compliance Consultant, Independent Auditor, Third-Party Accountant, Special Compliance Official, Independent Ethics Reviewer, Corporate Monitor and Monitor". International Association of Independent Corporate Monitors (IAICM). Disponível em: http://iaicm.org/. Acesso em 11 de julho de 2020). Segundo a American Bar Association, os termos "external compliance officer" e "Independent Private Secto Inspectors General" também são utilizados para se referir a Monitores. Vide "ABA Standards for (4th Monitors ed.)". https://www.americanbar.org/groups/criminal_justice/standards/MonitorsStandards/. Acesso em 11 de julho de 2020.
}

${ }^{2}$ Como analisaremos ao longo deste trabalho, a licitude está relacionada à observância de todos os princípios e normas que regem a matéria no Brasil, tanto em relação ao processo ou procedimento que antecede a nomeação do Monitor quanto na sua inclusão como parte de um acordo ou de forma unilateral. 
destituição do Monitor, e as diretrizes para o desempenho da monitoria ${ }^{3}$. Ademais, a regulamentação também deve tratar das especificidades locais cabíveis à utilização de Monitores no âmbito judicial e administrativo, a garantir a adequabilidade e licitude do uso dessa ferramenta em cada esfera.

Como veremos, em um sistema fundamentado na tradição de "Civil Law", como a brasileira, a existência de legislação específica sobre ferramentas jurídicas alienígenas é fundamental para atribuir legitimidade à utilização de Monitores e reduzir a insegurança jurídica que atualmente envolve o tema. Sem isso, o uso desse mecanismo no Brasil, que expressa o interesse público de aprimorar a integridade empresarial em casos de corrupção, permanecerá carecendo da importância, extensão e adequação que requer.

Com efeito, insegurança jurídica e brechas legais nunca são desejáveis, mas são particularmente perigosas quando lidamos com grandes casos de corrupção, nos quais os mais diferentes e importantes interesses políticos e econômicos serão diretamente afetados.

Diante da multiplicidade de competências jurisdicionais em matérias de corrupção no Brasil, corre-se, ainda, o risco de que esse vácuo legislativo seja preenchido por normas emanadas por diferentes autoridades governamentais, o que aumenta a probabilidade de que sejam elaborados regramentos conflitivos e que priorizem interesses meramente institucionais, o que é particularmente problemático em um sistema jurídico com traços inquisitoriais remanescentes ${ }^{4}$, como o brasileiro.

Como parte da análise, e para fins metodológicos, pretende-se estudar, do ponto de vista legal, doutrinário e jurisprudencial, o que é o instituto do monitoramento, sua origem e

\footnotetext{
${ }^{3}$ Monitoria e monitoramento serão usados ao longo desta tese de forma indistinta. É possível encontrar menção aos dois termos em artigos sobre o tema e diferentes profissionais da área costumam possuir preferência por um dos termos em relação ao outro, sem que haja consenso sobre qual dos dois termos é o mais adequado. Preferimos, de todo modo, qualquer um desses termos do que o termo "auditoria externa", que pode gerar confusão com a tradicional ideia de "auditoria" para outros fins, como fiscais, trabalhistas ou mesmo investigação "shadow" cuja função é acompanhar paralelamente o andamento das investigações internas.

${ }^{4}$ Como analisaremos de forma detalhada neste trabalho, o ordenamento jurídico brasileiro possui origem na tradição "Civil Law". O sistema inquisitorial de persecução governamental está intimamente relacionado com a tradição "Civil Law". A despeito de o Brasil ter absorvido ao longo dos anos aspectos do sistema adversarial, na legislação pátria, ainda existem dispositivos típicos de um sistema inquisitorial, além de outros aspectos deste sistema que reverberam em instituições, procedimentos, aspectos culturais, etc.
} 
como, quando e por quais motivos um Monitor pode ser imposto ou negociado perante o Direito brasileiro com base nas diferentes legislações que tangenciam a matéria.

Por se tratar de um instituto oriundo no Direito estadunidense, analisaremos, de forma crítica, quais são os elementos substanciais e processuais do Sistema Adversarial (ou acusatória) e da realidade local que influenciam o tema do Monitor e que, consequentemente, precisam ser cuidadosamente adaptados para que haja compatibilidade com o Direito pátrio.

De modo a dar amparo teórico à análise que se pretende realizar, estudamos como a Alemanha, Argentina, França e Itália ${ }^{5}$, países cujos sistemas jurídicos têm origem romanogermânico, introduziram elementos da "justiça negociada" em ordenamentos jurídicos fundamentados na "Civil Law". Replicando a experiência desses países, analisaremos quais as compatibilizações necessárias e os desafios a serem enfrentados no que tange ao Direito brasileiro.

A partir da análise das similaridades entre estas jurisdições e o Brasil, especificamente no que se refere à compatibilidade ou não da "justiça negociada" e do Monitor, podemos antecipar os principais pontos que serão objeto de questionamento no Brasil e entender como outras jurisdições trataram o tema. Por outro lado, analisaremos aspectos específicos do Brasil para entender quando a incorporação deste instituto ao Direito pátrio traz benefícios ou desafios específicos.

A despeito de o estudo sobre impactos decorrentes da corrupção atual envolver acalorados debates de cunho partidário, a nossa proposta é analisar a discussão de forma puramente técnica e dogmática, retirando qualquer aspecto político da discussão.

A ideia é que o leitor possa percorrer esta tese de modo a visualizar o caminho de evolução, desafios e descobertas que percorremos do momento em que decidimos escrever sobre o tema sob a cuidadosa e apaixonada supervisão do Professor Newton De Lucca até a conclusão desta pesquisa. De fato, foram enfrentadas muitas questões nunca ou muito pouco

\footnotetext{
${ }^{5}$ Essas quatro jurisdições foram analisadas por Máximo Langer e as análises do autor foram consideradas neste trabalho (LANGER. Máximo. From Legal Transplants to Legal Translations: The Globalization of Plea Bargaining and The Americanization Thesis in Criminal Procedure. Harvard International Law Journal. Vol. 45. n. ${ }^{\circ}$ 1, Winter 2004).
} 
discutidas, até o momento, que resultaram na mudança e aperfeiçoamento sobre diversos conceitos pré-concebidos que tínhamos.

É por este motivo que uma pesquisa cujo escopo inicial era discutir especificamente a figura do Monitor com um enfoque mais prático, aos moldes de um "Guia para ser Monitor ou Monitorado", acabou por ter um enfoque predominantemente teórico e também analisar aspectos de Direito Constitucional, administrativo e penal.

Assim, são abordados assuntos como a presunção de inocência, prescrição, privilégio contra a autoincriminação, discricionariedade do acusador, diferentes sistemas jurídicos, problemas da justiça seletiva, responsabilidade penal da pessoa jurídica, além de muitos outros temas estruturais do Direito pátrio. Esses assuntos são tratados ao longo desta tese na medida em que forem relevantes à presente pesquisa, sem que nos percamos do enfoque principal que é o monitoramento anticorrupção.

Como um último esclarecimento introdutório, é importante contar um pouco sobre os principais eventos que nos influenciaram, o que é importante para que o leitor entenda o motivo e a forma como alguns temas são tratados ao longo desta tese.

$\mathrm{O}$ autor desta pesquisa advogou em casos que exigiram negociações com autoridades públicas no Brasil e no exterior e trabalhou no governo federal em matéria de antitruste. $\mathrm{O}$ orientador desta pesquisa, Professor Newton De Lucca, sempre incentivou o autor a analisar a questão da corrupção de forma profunda e filosófica, como algo repudiante e extremamente danoso ao País.

A banca de qualificação desta tese, que contou com a participação dos Professores Renata Mota Maciel e Roberto Augusto Castellanos Pfeiffer, provocou-nos a analisar a discussão de forma predominantemente teórica e com enfoque em anticorrupção (i.e., retirando a discussão da monitoria antitruste como tema central, o que era inicialmente proposto). A banca de qualificação foi, de fato, um evento transformador e alterou, por completo, o que apresentamos como produto final deste trabalho.

Por outro lado, o mestrado que o autor concluiu neste ano, na Universidade de Stanford, "contaminou" o autor com a necessidade de não analisar os problemas jurídicos de forma ordinária. Foi também em Stanford que o autor teve o privilégio de conhecer a 
Professora Maria Paula Costa Bertran ${ }^{6}$ que forneceu importantes sugestões sobre esta pesquisa.

Vale ainda destacar que o autor teve a oportunidade de conversar sobre o tema com acadêmicos, profissionais que atuaram ou atuam como Monitores e agentes públicos que representam ou representaram o governo em acordos envolvendo Monitores. Todas essas pessoas gentilmente dedicaram tempo e energia para nos auxiliar a aprimorar esta tese, motivo pelo qual aproveitamos para, mais uma vez, agradecê-los ${ }^{7}$.

Além disso, espera-se que esta pesquisa auxilie em futuras discussões envolvendo o monitoramento, seja na academia, no judiciário, no âmbito de um processo administrativo ou de reformas legislativas. Em particular, foi muito gratificante ver o interesse de Monitores e empresas monitoradas, acadêmicos e advogados de anticorrupção pela temática deste trabalho, os quais se queixam da atual absoluta falta de literatura sobre o tema no Brasil. Isso corrobora, não só a importância desta pesquisa, mas também sua novidade.

A expectativa é que esta tese seja um passo inicial, mas ao mesmo tempo decisivo, para que este tópico seja mais conhecido e mais bem compreendido no Brasil, bem como ajustado de forma adequada ao ordenamento jurídico pátrio.

\subsection{A relevância do tema}

Mais de seis anos transcorridos desde a deflagração da operação de busca e apreensão que obteve as primeiras provas no âmbito da Operação Lava-Jato ${ }^{8}$, o Brasil ainda vive um período de intenso caos político, jurídico e econômico.

\footnotetext{
${ }^{6}$ A Professora Maria Paula é Docente da Faculdade de Direito de Ribeirão Preto da USP e estava em Stanford ministrando o curso "Business, Institutions and Corruption in Latin America", no qual o autor foi aluno.

${ }^{7}$ Por solicitação desses profissionais, não indicaremos os seus nomes para evitar qualquer vinculação entre os seus nomes e as conclusões expostas nesta pesquisa.

8 A Operação Lava-Jato teve início em 17 de março de 2014. Esta operação unificou quatro investigações da Polícia Federal ("PF") que apuraram a prática de crimes financeiros e desvio de recursos públicos. A análise do material apreendido indicou o potencial envolvimento de agentes públicos e políticos em esquemas ilícitos de magnitude muito mais ampla do que os inicialmente investigados pela operação.
} 
Parte da população brasileira e mundial considera a Operação Lava-Jato como a maior representação da "luta contra a corrupção no Brasil", ao passo que outra parcela a vê como uma sofisticada manobra de determinados grupos políticos articulados, em particular de grupos da chamada "direita", para remover a suposta "esquerda" do poder no País e devolvêlo às elites 9 .

Independentemente de qualquer opinião política sobre o tema, o que fugiria por completo do objeto deste trabalho, a Operação Lava-Jato gerou inúmeros desdobramentos jurídicos, tanto no País, quanto no exterior, e isso é do nosso interessa para os fins desta tese.

Em particular, essa operação rendeu, até o momento, mais de 70 operações da PF, diversas investigações perante autoridades administrativas ${ }^{10}, 163$ prisões temporárias e outras 130 prisões preventivas, 1343 buscas e apreensões, 211 conduções coercitivas, 10 ações de improbidade administrativa, 138 acordos de colaboração, mais de $\mathrm{R} \$ 14$ bilhões previstos de recuperação aos cofres públicos ${ }^{11}$ e cerca de 40 pedidos passivos de cooperação jurídica internacional em matéria penal, além de outros desdobramentos ${ }^{12}$.

No meio dessa enxurrada de processos judiciais e administrativos, foram celebrados, no final de 2016, dois acordos particularmente relevantes para o tema que se pretende tratar nesta tese, pois resultaram na nomeação de Monitores no Brasil. Até a celebração desses acordos, o único outro Monitor envolvendo empresa brasileira havia sido em um acordo firmado no caso Embraer S.A. ("Embraer") ${ }^{13}$, poucos meses antes desses acordos, em outubro de 2016.

\footnotetext{
9 Disponível em: https://operamundi.uol.com.br/politica-e-economia/59896/juristas-estrangeiros-dizem-quelula-e-vitima-de-perseguicao-politica-e-pedem-libertacao-de-ex-presidente. Acesso em 19 de julho de 2020.

${ }^{10}$ Vide, por exemplo, as operações do cartel de Angra 3 e Belo Monte perante o Conselho Administrativo de Defesa Econômica ("CADE”).

11 Mais de R \$ 4 bilhões já foram devolvidos aos cofres da Petrobras, União, etc.

12 Disponível em: http://www.mpf.mp.br/grandes-casos/lava-jato/resultados e http://www.mpf.mp.br/grandescasos/lava-jato/efeitos-no-exterior. Acesso em 10 de junho de 2020.
}

13 A despeito de este ter sido o primeiro caso envolvendo o monitoramento de uma empresa brasileira, outros casos de monitoramento global envolveram o monitoramento de atividades desenvolvidas por multinacionais com atividades no Brasil (e.g., ABB, Siemens, Avon e Monsanto). Nesses casos, e na ausência de uma investigação local, os acordos ou decisões não envolvem autoridades brasileiras e, portanto, são firmados sem levar em conta a legislação local. 
No Brasil, ambos os acordos envolveram, de um lado, o Ministério Público Federal ("MPF") ${ }^{14}$ e, do outro, empresas investigadas na Operação Lava-Jato - Braskem S.A. (“Braskem”) e Odebrecht S.A. (“Odebrecht”). Já no âmbito internacional, acordos foram celebrados entre as mesmas empresas citadas e autoridades estadunidenses, o "U.S. Department of Justice" ("DOJ") e a "Securities and Exchange Commission"15 ("SEC"), além da Procuradoria-Geral da Suíça.

Esses acordos, em conjunto com uma série de outras investigações relacionadas ao esquema de corrupção no Brasil e no exterior investigados no âmbito da Operação Lava-Jato, contribuíram para o desmantelamento de uma série de condutas de corrupção que afetaram de forma intensa empresas públicas e privadas ${ }^{16}$.

Como parte do acordo, e conforme será detalhado mais adiante, as empresas confessaram o cometimento de práticas de corrupção, concordaram em pagar multas altíssimas, comprometeram-se a cooperar com as autoridades públicas, bem como assumiram a obrigação de contratar Monitores.

Uma vez celebrados acordos nos Estados Unidos da América ("EUA”) prevendo a nomeação de Monitores, a incorporação dessa obrigação se tornou quase que automática nos acordos firmados com as autoridades brasileiras ${ }^{17}$.

Mais recentemente, contudo, outros dois acordos prevendo a nomeação de Monitores foram celebrados envolvendo empresas brasileiras. Esses dois outros casos envolvem a J\&F Investimentos S.A. (“J\&F), em 2017, e a Rodonorte - Concessionária de Rodovias Integradas

\footnotetext{
14 Para os fins deste trabalho, a sigla "MP" abarca referências conjuntas e indistintas ao MPF e aos diversos Ministérios Públicos Estaduais. A sigla "MPE” refere-se apenas à Ministério Público Estadual.

15 A SEC celebrou acordo apenas com a Braskem, pois a Odebrecht não era uma emissora EUA.

16 No caso da Odebrecht, a então gigante do mercado de construção teria organizado uma sofisticada unidade de negócios secreta para o pagamento de propina, denominada de Departamento de Operações Estruturadas. Esta divisão de negócios pagou centenas de milhões de dólares em propina em diversos países em três continentes distintos.

${ }^{17} \mathrm{Ou}$ seja, como as autoridades estadunidenses decidiram impor o monitoramento, as empresas já estariam de uma forma ou outra sob o monitoramento. Por conta disto, prever isso nos acordos locais no caso da Odebrecht e Braskem se tornou algo muito mais simples e, inclusive, evita que as autoridades locais deixem transparecer que estão sendo mais lenientes do que as estrangeiras.
} 
S.A. ("Rodonorte"), em 2019. Tratam-se dos dois primeiros acordos envolvendo Monitores como parte de acordos firmados apenas com autoridades brasileiras.

Esses cinco casos serão analisados mais adiante, mas vale destacar que todos esses acordos envolvendo Monitores foram celebrados nos últimos quatro anos, a despeito de este instituto já ser utilizado ao menos desde 1995 pelo DOJ e, desde 1978, pela SEC ${ }^{18}$. Ou seja, trata-se de um instituto novo e, ao menos no Brasil, em ascensão ${ }^{19}$.

Para alguns, contudo, o aumento na utilização de Monitores no Brasil é um indicativo de que a persecução penal pelos EUA segue um padrão de "mirar" em algumas jurisdições específicas por motivos políticos e econômicos e o Brasil foi "a bola da vez"20, assim como a China está na "mira" do DOJ desde a edição da chamada "China Initiative", em novembro de $2018^{21}$.

Note-se, ainda, que nunca houve no Brasil a nomeação de um Monitor como parte de um acordo firmado com autoridade administrativa, como a Controladoria-Geral da União (“CGU”) ou com o CADE, bem como para temas não relacionados à corrupção. Nada obstante, este trabalho se propõe a indicar uma série de princípios e normas que devem ser cuidadosamente observadas quando isso ocorrer.

\footnotetext{
18 Vide James C. McKinley, Con Ed Fined and Sentenced to Monitoring for Asbestos Cover-Up, N.Y. Times (22 de abril de 1995). Disponível em: www.nytimes.com/1995/04/22/nyregion/con-ed-fined-and-sentenced-toMonitoring-for-asbestos-cover-up.html. Acesso em 11 de julho de 2020. Vale notar que o DOJ não foi a primeira autoridade a utilizar um Monitor. A SEC, por exemplo, utilizou Monitores ainda em 1978, vide "SEC News Digest", "Issue" $80-71$ p. 3 (10 de abril de 1980). Disponível em: https://www.sec.gov/news/digest/1980/dig041080.pdf. Acesso em 11 de julho de 2020.

${ }^{19}$ Vale lembrar, contudo, que autoridades do governo estadunidense pertencentes à administração do governo Donald Trump têm levantado questionamentos sobre a utilização deste mecanismo. Disponível em: https://www.forbes.com/sites/insider/2018/10/15/rethinking-corporate-Monitors-doj-tells-companies-to-mindtheir-own-business/\#4c17b7745b41. Acesso em 11 de julho de 2020.
}

${ }^{20}$ A título de exemplo, segundo dados de 2017 do "FCPA Blog", de 104 empresas que divulgaram estarem sendo investigadas nos EUA por potenciais práticas de corrupção no exterior, 30 empresas mencionaram o Brasil como um território afetado. Disponível em: https://fcpablog.com/2017/05/19/thirty-companies-name-brazil-inconnection-with-fcpa-related/. Já segundo dados de 2018 do "FCPA Blog", o Brasil foi mencionado em 36 investigações de um total de 138 divulgadas em 2018. Disponível em: https://fcpablog.com/2018/04/26/brazilchina-most-mentioned-in-fcpa-related-investigations/. Segundo o "FCPA Blog", o Brasil seguiu como a jurisdição mais mencionada em 2019. Disponível em: https://blog.fcpatracker.com/2020/01/fcpa-investigationsyear-in-review-2019/.

${ }^{21}$ Vide: https://www.justice.gov/opa/speech/file/1107256/download. 
A celebração desses cinco acordos que, como vimos, por ora ocorreram apenas no contexto judicial, envolveu uma série de questões controvertidas e inéditas do ponto de vista jurídico, em particular no que tange à competência para assinar e aprovar acordos dessa natureza no Brasil, quais seriam os seus efeitos e limitações e sobre a possibilidade, adequação e regras que devem ser seguidas para que um Monitor possa ser nomeado segundo o ordenamento jurídico pátrio.

Não há, contudo, normas específicas sobre a matéria e, caso não haja a regulação adequada sobre o tema, a tendência é que um regramento seja elaborado de forma unilateral pela própria instituição acusadora que é parte do processo (e.g., pelo próprio MP ou pela $\mathrm{CGU}^{22}$ ) e que, portanto, não possui a isenção, imparcialidade e legitimidade para disciplinar um acordo envolvendo um Monitor de forma adequdaa.

De mais a mais, e como analisado na obra de Máximo Langer ${ }^{23}$, sistemas jurídicos de tradição no "Sistema de Civil Law", como o Brasil, possuem características próprias e profundas diferenças teóricas e práticas em relação ao sistema consuetudinário estadunidense, de origem no "Sistema de Common Law", que serão analisadas neste trabalho. Essas “diferenças relativas entre as tradições jurídicas persistem (ainda que menos pronunciadas do que no passado) e continuam a merecer a atenção de comparatistas e operadores do Direito"24.

Os acordos firmados no Brasil que envolvem a utilização de Monitores, bem como o próprio conceito de "justiça negociada", possuem origem na lógica adversarial (ou acusatória), presente de forma predominante nos países de tradição "Common Law”.

Como veremos, esses acordos decorrem de um arcabouço legislativo e institucional, bem como de aspectos culturais, sociais e econômicos que são inexistentes ou diferentes localmente. Há, por exemplo, regramento próprio e detalhado no Brasil sobre como autoridades administrativas devem atuar, em particular, no contexto de processos

\footnotetext{
${ }^{22}$ Isso ocorreria, por exemplo, por meio das instruções, portarias, etc. emitidas pela própria instituição.

${ }^{23}$ LANGER. Máximo. From Legal Transplants to Legal Translations: The Globalization of Plea Bargaining and The Americanization Thesis in Criminal Procedure. Harvard International Law Journal. Vol. 45. n. ${ }^{\circ}$, Winter 2004.
}

${ }^{24}$ PARGENDLER, Mariana. O direito contratual comparado em nova perspectiva: revisitando as diferenças entre os sistemas romano-germânico e de common law. In. Revista Direito GV. V. 13. n. ${ }^{\circ}$ 3. set/dez. 2017. p 800. 
sancionadores, e o mesmo sobre a atuação de promotores e juízes no âmbito judicial, diante das particularidades de cada sistema jurídico.

A despeito da celebração de cinco acordos envolvendo Monitores, não houve deliberação sobre a legalidade, legitimidade e limites dos acordos celebrados, fazendo com que o tratamento jurídico do tema permaneça obscuro. Essas nuances não foram esmiuçadas detalhadamente por uma série de motivos de ordem prática e econômica, em particular pelo "pacto de sujeição" decorrente da desproporcionalidade de força entre acusação e defesa nesses processos e o interesse das empresas em encerrar as investigações de forma rápida e completa por motivos reputacionais e econômicos ${ }^{25}$.

Apesar de esses elementos não terem sido profundamente discutidos no contexto desses acordos, são questões cruciais que seguem vivas em nosso sistema jurídico e, cedo ou tarde, serão objeto de questionamento jurídico. Esses embates podem se dar tanto em um caso concreto, como no âmbito de uma alteração legislativa mais ampla. De qualquer forma, como veremos, é de se esperar que institutos existentes no sistema jurídico de outros países precisem de ajustes relevantes para que se tornem compatíveis com o sistema jurídico e com a realidade de outra jurisdição, neste caso, a brasileira.

A tendência da necessidade de ajustes no que se refere à internalização de institutos alienígenas é mais notável quando se importam aspectos tradicionais de um tipo de sistema jurídico para outro (ou seja, do "Sistema de Common Law" para o "Sistema de Civil Law"), como ocorre no caso da importação para o Brasil dos "plea bargaining" e do Monitor do sistema estadunidense. De forma mais específica, do Sistema Adversarial para o Sistema Inquisitorial.

O fato de a "justiça negociada” já fazer parte da realidade do sistema jurídico pátrio, uma vez que já existe a possibilidade de uma série de acordos no âmbito penal, administrativo e cível, inclusive para temas de corrupção, não significa que esses acordos não precisem sofrer adaptações adicionais para que sejam adequadamente incorporados ao sistema pátrio de origem no "Sistema de Civil Law".

\footnotetext{
${ }^{25}$ No contexto dessas investigações, havia um interesse em encerrá-las, proteger as pessoas físicas, facilitar a captação de recursos e provisionar os prejuízos. Por este motivo, muito do que poderia ter sido questionado não foi, na perfeita representação de sanção como poder em um contexto no qual questionar a legitimidade seria mais custoso do que aceitar a pena.
} 
A razão para este argumento é que neste sistema seria de se esperar existir uma predominância do Sistema Inquisitorial, a despeito de aspectos do Sistema Adversarial já terem sido introduzidos no Brasil, em particular após a entrada em vigor da Constituição Federal de 1988.

Como veremos ao longo deste trabalho, o mesmo ocorre quando observamos a incorporação de mecanismo de "justiça negociada", como os "plea bargainings", em outros países de tradição "Civil Law". No caso, analisamos essa questão na Alemanha, Argentina, Itália e França, bem como no Brasil, seguindo e complementando a análise de Máximo Langer ${ }^{26}$.

Assim, e a despeito de a tese em si ser mais restrita e focar nos Monitores, este trabalho abarca não só o estudo do instituto do Monitor no Direito brasileiro, mas também dos acordos administrativos e judiciais em temas de corrupção. O enfoque é predominantemente teórico, sem perder de vista os aspectos práticos da discussão.

A pesquisa envolve, portanto, um mecanismo relacionado com o aumento da integridade empresarial, o que é um dos assuntos mais importantes e debatidos da atualidade, mas muito pouco ou nada estudado do ponto de vista teórico e para fins acadêmicos.

O tema, além de atual e inédito, é inegavelmente relevante. Ao mesmo tempo em que as autoridades públicas investigam e punem práticas de corrupção, os empresários brasileiros encontram-se assustados com a possibilidade de que suas empresas e seus próprios nomes estejam envolvidos em um escândalo decorrente da falta de integridade empresarial, cuja maior manifestação seria o envolvimento em esquemas de corrupção.

Investidores nacionais e estrangeiros, colaboradores, empregados, fornecedores e clientes também atribuem cada vez mais importância ao tema da corrupção, sendo que, no geral, há mais receio ou uma restrição total em interagir com empresas que atuam de forma não íntegra.

\footnotetext{
${ }^{26}$ LANGER. Máximo. From Legal Transplants to Legal Translations: The Globalization of Plea Bargaining and The Americanization Thesis in Criminal Procedure. Harvard International Law Journal. Vol. 45. n. ${ }^{\circ}$, Winter 2004.
} 


\subsection{O problema da corrupção}

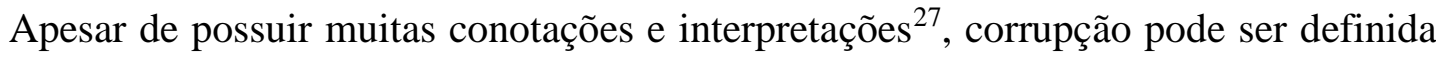
como uma conduta ilegal na qual uma parte assume uma obrigação de dar, fazer ou não fazer em troca da promessa de uma contraprestação que não poderia ser concedida da forma ou no momento prometido ${ }^{28}$.

Ao seu turno, é possível classificar tipos de corrupção com base na conduta específica, como pagamento de propina, extorsão, troca de favores, nepotismo, determinados tipos de fraude judicial, contábil, eleitoral, licitação, etc ${ }^{29}$.

No que tange aos seus partícipes, de maneira geral, a corrupção pode envolver quatro categorias de agentes: (i) políticos; (ii) funcionários públicos; (iii) empresários; e (iv) cidadãos comuns $^{30}$.

Definidos os elementos constitutivos e passando para análise de sua genealogia, temos que a corrupção é um "fenômeno multifacetado - social, político, econômico e cultural, que se desenvolve sobremodo por meio de organizações, sem embargo de concretizar-se por iniciativas isoladas de agentes públicos, que atuam em prol de interesses privados por meio de troca bilateral que gera vantagens indevidas" 31 .

O Professor Vicente Greco (2015, p. 15/16) leciona o quanto segue:

\footnotetext{
${ }^{27}$ Vide ROSE-ACKERMAN, Susan., \& Palifka, Bonnie J.. Corruption and Government: Causes, Consequences, and Reform. Cambridge: Cambridge University Press. 2016. p. 7.

28 "Corruption is an extra-legal institution used by individuals or groups to gain influence over the actions of the bureaucracy. As such, the existence of corruption per se indicates only that these groups participate in the decision-making process to a greater extent than would otherwise be the case" (LEFF. Nathaniel. "Economic Development Through Bureaucratic Corruption.” American Behavioral Scientist. Nov. 1964).

${ }^{29}$ Vide ROSE-ACKERMAN, Susan., \& Palifka, Bonnie J.. Corruption and Government: Causes, Consequences, and Reform. Cambridge: Cambridge University Press. 2016. p. 8.

${ }^{30}$ FISMAN. Ray. GOLDEN. Miriam A. Corruption: What Everyone Needs to Know. Oxford University Press, 2017. p. 4.

${ }^{31}$ Nota Técnica n. ${ }^{\circ}$ 1/2017 - 5ª Câmara de Coordenação e Revisão (Combate à Corrupção), do MPF, p. 5. Disponível em: http://www.mpf.mp.br/atuacao-tematica/ccr5/notas-tecnicas/docs/nt-01-2017-5ccr-acordo-deleniencia-comissao-leniencia.pdf. Acesso em 11 de julho de 2020.
} 
o problema da corrupção, assim, é amplo, envolvendo, na verdade, qualquer locupletamento indevido decorrente da prática de ato ilegal ou mesmo antiético para beneficiar alguém ou facilitar alguma atividade, ainda que legítima de outrem, ou, ainda, comportar-se de maneira indevida para obter algum benefício para si ou para outrem, ainda que sem conteúdo econômico ${ }^{32}$.

Por motivos óbvios (i.e., intenção de ocultar a prática e a impossibilidade de execução judicial do acordo dada sua ilicitude), esquemas envolvendo corrupção costumam se realizar de forma oral e com prestações bilaterais que não são proporcionais.

Ilustrando-se o quanto informado acima, o dono de uma concessionária de veículos promete vender um veículo a preço de custo para um fiscal da Receita Federal se ele não aplicar multa que poderia ser muito superior ao valor de um veículo. O motivo para a desproporção entre os valores das prestações de cada parte decorre do fato de que, na maioria das vezes, o objeto deste acordo ilegal é algo que pode beneficiar uma das partes sem gerar custos para quem "entrega" o benefício (e.g., concessão de uma autorização para construção de um empreendimento imobiliário).

Keith J. Rosenn define corrupção como um comportamento desonesto que beneficia um indivíduo às expensas do Estado ${ }^{33}$. Obviamente, contudo, não é apenas o Estado que se prejudica com a corrupção. Concorrentes da empresa corrupta, por exemplo, também se prejudicam, assim como a população de forma ampla, uma vez que corrupção gera má alocação e desperdícios de recursos privados e públicos.

Infelizmente, corrupção não é uma novidade no Brasil, sendo parte da nossa história, como retratado na obra clássica "Os donos do poder: formação do patronato político brasileiro", de Raymundo Faoro (2001, p. 480):

Depois de 1850, na acelerada onda que sucede à tímida, mas ascendente, economia cafeeira, com o dinheiro do tráfico jorrando no Rio de Janeiro, o país ferve de euforia, euforia sustentada por uma real expansão da renda. "Desde o princípio," - recordará um aristocrata, saudosamente enamorado da austeridade olvidada - "o calor, a luz, a vida para as maiores empresas, tinham vindo do Tesouro. Em todo tempo, as grandes figuras financeiras,

\footnotetext{
32 GRECO FILHO, Vicente; ROSSI, João Daniel, O combate à corrupção à Lei de Responsabilidade de Pessoas Jurídicas, 2015, p.15 e 16.

33 "Dishonest behavior benefiting an individual at the expense of the state." (ROSENN. Keith J. "Brazil's Legal Culture: The Jeito Revisited.” Florida International Law Journal. 1. 1984. p. 4).
} 
industriais, do país tinham crescido à sombra da influência e proteção que lhes dispensava o governo; esse sistema só podia dar em resultado a corrupção e a gangrena da riqueza pública e particular ${ }^{34}$.

As causas da corrupção podem ser várias, mas no Brasil parece-nos que dois elementos merecem maior destaque, quais sejam: (i) a burocracia relacionada à atuação do Estado; e (ii) a intensa presença do governo na atividade econômica.

Muitos também atribuíram um aspecto "cultural” e "histórico" à corrupção brasileira, mas é impossível se afirmar, com exatidão, se esses dois elementos indicados acima (i.e., burocracia e intensa presença do Estado na economia) moldaram a "cultura" brasileira ou o contrário. É certo, contudo, que uma série de elementos históricos, inclusive relacionados à forma de colonização brasileira, criaram um ambiente no qual se tem a percepção de que a corrupção é constante, profunda, disseminada e sistêmica em nosso País ${ }^{35}$.

A burocracia, apesar de não justificar ou servir como defesa, é uma causa da corrupção, pois ela representa um obstáculo aos particulares, o que aumenta os custos de se operar qualquer negócio no Brasil ${ }^{36}$.

Configura-se, então, a tradicional situação na qual a dificuldade existente para se conseguir qualquer coisa perante o governo se amplifica pela dificuldade criada pelo próprio agente público e "surge", então, a possibilidade de se "resolver" os problemas mediante o famoso "jeitinho brasileiro". Em outras palavras, criam-se dificuldades para se vender facilidades. A Administração Pública, ao seu turno, justifica a criação de processos burocráticos para evitar desvios e corrupção, em um ciclo nefasto que se retroalimenta.

34 FAORO, Raymundo. Os donos do poder: formação do patronato político brasileiro. $3^{\mathrm{a}}$ ed., São Paulo: Globo, 2001, p. 480.

35 Vide: LEFF. Nathaniel. "Economic Development Through Bureaucratic Corruption." American Behavioral Scientist. Nov. (1964); ALA'J. Padideh. "The Legacy of Geographical Morality and Colonialism: A Historical Assessment of the Current Crusade Against Corruption." Vanderbilt Journal of Transitional Law, Vol. 33, No. 4, October (2000).

36 Sobre o tema: "We should also distinguish between bureaucratic corruption and bureaucratic inefficiency. Corruption refers to extra-legal influence on policy formulation or implementation. Inefficiency, on the other hand, has to do with the success or failure, or the economy of means used by the bureaucracy in attaining given goals, whether those of its political directors, or those of the grafters. Empirically, inefficiency and corruption may appear together, and may blend into each other. Both as a policy problem and for analytical purposes, however, it is important to distinguish between two essentially different things" (LEFF. Nathaniel. "Economic Development Through Bureaucratic Corruption.” American Behavioral Scientist. Nov. 1964). 
Na obra "Brazil's Legal Culture: The Jeito Revisited”, Keith J. Rosenn traz algumas definições para explicar o termo "jeitinho brasileiro", que, em última análise, representa uma forma brasileira não ortodoxa de resolução de "obstáculos”, seja por meios lícitos ou ilícitos, mas sempre por meio de um desvio do comportamento padrão.

$\mathrm{Na}$ linha desta definição, a obra acima pontua que o "jeitinho brasileiro" ocorre em diversos tipos de situações e gera diferentes impactos à sociedade. Cada situação, contudo, possui diferentes enquadramentos jurídicos e morais, com impactos distintos à coletividade.

Na obra citada, o "jeitinho" é classificado nas seguintes cinco formas:

Tabela 1- Elementos do "jeitinho" brasileiro

\begin{tabular}{|c|c|}
\hline Tipo de "jeitinho" & Descrição \\
\hline $\begin{array}{l}\text { Um agente do governo deixa de cumprir sua } \\
\text { obrigação legal em troca de um benefício pessoal. }\end{array}$ & \multirow[t]{2}{*}{$\begin{array}{l}\text { Estas práticas se enquadram na definiç̧ão tradicional } \\
\text { de corrupção. }\end{array}$} \\
\hline $\begin{array}{l}\text { Um cidadão usa um subterfúgio para não cumprir } \\
\text { uma obrigação legal justa segundo uma análise } \\
\text { objetiva. }\end{array}$ & \\
\hline $\begin{array}{l}\text { Um agente público cumpre as suas funções de forma } \\
\text { rápida apenas se receber de um particular algum } \\
\text { benefício indevido em troca. }\end{array}$ & $\begin{array}{l}\text { Esta conduta também se enquadra na definição } \\
\text { tradicional de corrupção, mas é menos ofensiva do } \\
\text { ponto de vista moral (por ser menos socialmente } \\
\text { reprovável). }\end{array}$ \\
\hline $\begin{array}{l}\text { Um cidadão escapa de uma obrigação legal que é não } \\
\text { realista, injusta ou ineficiente do ponto de vista } \\
\text { econômico. }\end{array}$ & \multirow[t]{2}{*}{$\begin{array}{l}\text { Situações nas quais o interesse público seria } \\
\text { alegadamente atingido por meio da não observância } \\
\text { da regra vigente. }\end{array}$} \\
\hline $\begin{array}{l}\text { Um agente público se desvia da sua obrigação legal, } \\
\text { pois sua convicção é que a lei é irrealista, injusta ou } \\
\text { ineficiente do ponto de vista econômico. }\end{array}$ & \\
\hline
\end{tabular}

Embora o Brasil tenha elementos que, estruturalmente, facilitem a corrupção, qualquer empresa ou instituição pode se envolver em corrupção, em qualquer lugar do mundo e independentemente do seu setor de atuação. O risco específico ao qual uma organização está exposta varia, contudo, com base no mercado de atuação da empresa, seu tamanho, posição de mercado, objetivos, clientes, regras de governança corporativa e de conformidade, etc. 
Como também se pode notar pelos diversos escândalos recentes, em particular, no âmbito da Operação Lava-Jato, vê-se que esse problema segue presente. Como diz o orientador deste trabalho, Professor Newton De Lucca, "corrupção é um dos pecados maiores do nosso tempo. Não preciso de explicar muito, porque ela está à vista de todos, no nosso país e nas notícias que nos chegam dos outros"37.

De fato, corrupção é um gravíssimo problema global, com acentuada penetração no Brasil. Segundo o "Corruption Perceptions Index 2018”, elaborado pela Transparência Internacional, o Brasil estava na $105^{\mathrm{a}}$ posição de país com mais corrupção em uma lista de 180 países $^{38}$. No "ranking” de 2019, divulgado em janeiro de 2020, o Brasil piorou e caiu mais uma posição, para o $106^{\text {a }} \operatorname{lugar}^{39}$.

De mais a mais, segundo dados de 2017 do "FCPA Blog", de 104 empresas que divulgaram estarem sendo investigadas nos EUA por potenciais práticas de corrupção no exterior, 30 empresas mencionaram o Brasil como um território afetado pela conduta (China foi o segundo país mais mencionado, com 17 menções, seguido pela Polônia e Índia, com três menções cada ${ }^{40}$. Já segundo dados de 2018 do "FCPA Blog", o Brasil foi mencionado em 36 investigações de um total de 138 divulgadas em 2018 ${ }^{41}$. Segundo o "FCPA Blog", o Brasil seguiu como a jurisdição mais mencionada em $2019^{42}$.

Os impactos causados pela divulgação de práticas de corrupção podem ser devastadores às empresas, instituições e indivíduos, tanto do ponto financeiro, quanto reputacional. A sociedade, ao seu turno, está farta de corrupção e as autoridades, governamentais estão mais agressivas do que nunca no combate a essas práticas.

\footnotetext{
${ }^{37}$ Disponível em: http://estadodedireito.com.br/a-corrupcao-da-lei-a-misericordia-tambem-corrompe/. Acesso em 10 de junho de 2020 .

${ }^{38}$ Disponível em: https://www.transparency.org/cpi2018. Acesso em 10 de junho de 2020.

${ }^{39}$ Disponível em: https://www.transparency.org/country/BRA. Acesso em 10 de junho de 2020.

40 Disponível em: https://fcpablog.com/2017/05/19/thirty-companies-name-brazil-in-connection-with-fcparelated/. Acesso em 10 de junho de 2020.
}

41 Disponível em: https://fcpablog.com/2018/04/26/brazil-china-most-mentioned-in-fcpa-relatedinvestigations/. Acesso em 10 de junho de 2020.

42 Disponível em: https://blog.fcpatracker.com/2020/01/fcpa-investigations-year-in-review-2019/. Acesso em 10 de junho de 2020 . 
Com efeito, a corrupção prejudica o crescimento econômico e o desenvolvimento social na medida em que gera a alocação ineficiente dos recursos e impede que valores sejam investidos em áreas essenciais, como saúde, educação, segurança e infraestrutura. Corrupção também compromete o bom funcionamento da democracia e do livre e justo mercado.

De mais a mais, empresas corruptas não são boas para a economia, pois enfraquecem o livre mercado ao permitirem que empresas ganhem ou mantenham negócios de forma artificial sem ofertar os melhores preços, qualidade e serviços.

Vimos, portanto, que corrupção é um tópico importante e atual. Sendo o tema dos Monitores algo novo no Brasil, complexo e diretamente relacionado à discussão sobre formas de se combater a corrupção. Portanto, o seu estudo é necessário e contemporâneo. 


\section{CONCLUSÃO}

O tema dos Monitores anticorrupção é relevante e moderno. Trata-se de uma ferramenta polêmica e custosa, mas muitas vezes efetiva para se combater a corrupção e assegurar o cumprimento das obrigações assumidas com as autoridades de combate à corrupção. Em muitos casos, a imposição do Monitor também serve para dar credibilidade aos esforços de remediação, pois há um terceiro externo supervisionando a empresa.

A discussão é particularmente complexa no Brasil, pois existem inúmeras autoridades públicas que cuidam de temas de corrupção de forma direta no País, no nível Federal, Estadual e municipal, como o MPF, MPE, CGU, Tribunais de Contas, e, de forma reflexa, CADE, $\mathrm{CVM}^{352}$, entre outras, cada uma com competência para aplicar determinadas leis que resultam em sanções de naturezas distintas (i.e., administrativa, penal, civil). Existem, ainda, interações com autoridades estrangeiras, o que adiciona complexidade à discussão.

Além da questão da legalidade, essa questão da diversidade de autoridades e poderes também interfere nos incentivos para que determinadas soluções sejam dadas para os casos, incluindo nessa discussão a questão sobre a nomeação de um Monitor que, até o momento, só ocorreu no Brasil como parte de acordos e perante o Poder Judiciário.

Como vimos acima, corrupção gera danos a bens jurídicos relevantes e, como é de se esperar, a sua prática pode ser sancionada no País por diversos instrumentos jurídicos. Notamos, ao longo deste trabalho, que acordos envolvendo a indicação de Monitores já ocorreram no território nacional. Esses acordos, mais do que envolverem empresas nacionais, contaram com a participação de autoridades locais.

Vimos que, no Brasil, uma série de normas atribuem poderes e regras específicas no que se refere à possibilidade de imposição de sanção e celebração de um acordo em temas de corrupção. Cada uma dessas normas prevê um tipo de procedimento ou processo distinto que exige a observância de determinadas regras e princípios. A multiplicidade de normas jurídicas e de seus conteúdos comprometem a integridade do sistema, sua coerência e previsibilidade.

\footnotetext{
352 A CVM, por exemplo, instaurou diversos processos para investigar os impactos societários causados pela corrupção no âmbito da Operação Lava-Jato. Disponível em: https://webcache.googleusercontent.com/search?q=cache:xDQAk8WflmwJ:https://economia.estadao.com.br/n oticias/geral,cvm-julgara-em-dezembro-primeiros-casos-sobre-petrobras-decorrentes-da-lavajato,70003093995+\&cd=1\&hl=pt-BR\&ct=clnk\&gl=br. Acesso em 11 de julho de 2020.
} 
A adoção de acordos no âmbito cível, administrativo ou penal prevendo a imposição de um Monitor se enquadra no contexto mais amplo de buscar tornar o processo mais eficiente e eficaz. Esses acordos permitem a redução de custos associados à persecução da violação, melhor alocação de recursos (i.e., priorização de casos) e, em especial, permite que alguma consequência decorrente do acordo seja aplicada em casos nos quais a acusação vislumbrava baixa chance de êxito no processo por questões formais. Ademais, esses acordos permitem que outras violações sejam descobertas por conta da colaboração do acusado no que se refere à entrega de novas provas.

Parece-nos, nessa linha de pensamento, que as autoridades, advogados e empresas brasileiras estão ainda aprendendo como, quando e por quais motivos um Monitor deve ser utilizado. Por outro lado, já vemos uma tendência à retração na utilização de Monitores nos EUA, como se pode inferir das políticas sobre a utilização de Monitores de 2018 editadas pelo DOJ.

Vimos, ainda, que a solução de investigações governamentais via acordo não faz parte da cultura brasileira, a despeito de já estar parcialmente incorporada no sistema jurídico pátrio. Contudo, a incorporação de aspectos do direito estadunidense não precisa e não deve seguir o estilo "tudo ou nada" 353 .

Por exemplo, Máximo Langer ${ }^{354}$ defende que o modelo da investigação oficial pode internalizar os acordos de confissão desde que esses acordos sejam usados como ferramenta para se descobrir a verdade e não como forma de solucionar os casos de forma rápida e barata (2004, p.63).

Consequentemente, propõe-se um sistema adaptado para o Brasil. Ou seja, reconhecemos as vantagens que podem advir de um monitoramento corporativo nos moldes adotados nos EUA, mas não acreditamos que a simples importação de mecanismos do direito

\footnotetext{
${ }^{353}$ LANGER. Máximo. From Legal Transplants to Legal Translations: The Globalization of Plea Bargaining and The Americanization Thesis in Criminal Procedure. Harvard International Law Journal. Vol. 45. n. ${ }^{\circ}$ 1, Winter 2004. p. 63.

${ }^{354}$ LANGER. Máximo. From Legal Transplants to Legal Translations: The Globalization of Plea Bargaining and The Americanization Thesis in Criminal Procedure. Harvard International Law Journal. Vol. 45. n. ${ }^{\mathbf{o}}$ 1, Winter 2004. p. 42.
} 
estadunidense funcione obrigatoriamente no Brasil, seja do ponto de vista legal, seja do ponto de vista prático.

Parece-nos, ainda, que mudanças legislativas poderiam ser implementadas de forma conjunta e integrada de modo a aprimorar a regulamentação do tema no Brasil. Essa regulamentação, para atingir os objetivos almejados, deve incluir regras específicas sobre quando um Monitor deve ser utilizado, como deve ser o processo de nomeação e como a monitoria deve se realizar, à luz do quanto analisado acima. Deve, ainda, levar em conta o regramento específico que deve ser seguido no caso da utilização de Monitores no âmbito judicial e administrativo para que a utilização dessa ferramenta seja lícita e eficiente.

De mais a mais, argumenta-se, ainda, que o sistema jurídico pátrio admite, desde que observadas normas próprias, apenas a nomeação de Monitores no âmbito de acordos administrativos e judiciais, e não de forma unilateral pela autoridade pública administrativa ou pelo juiz. Por esse motivo, o monitoramento, que pode ser absolutamente necessário e conveniente em determinados casos, não pode ser determinado nos casos em que a empresa decide litigar até o final, não reconhece culpa e não aceita melhorar o seu programa de conformidade e controles internos.

Uma legislação específica sobre a matéria é fundamental em uma jurisdição como a brasileira, de tradição no "Sistema de Civil Law", como forma de se atribuir legitimidade à utilização de Monitores e reduzir a insegurança jurídica que atualmente envolve o tema. Sem isso, esse mecanismo de expressão do interesse público em casos de corrupção não possuirá a importância e adequação necessárias no Brasil.

Além disso, e em vez da possibilidade de dissolução da empresa, a lei deveria obrigar a "transferência de controle societário, venda de ativos ou cessação parcial de atividade" quando a alta administração se envolver em corrupção de forma reincidente dentro de determinado período após um monitoramento (e.g., 5 anos). Ou seja, uma empresa que comete corrupção é condenada, passa por um monitoramento e volta a cometer as mesmas infrações precisa mudar definitivamente de mãos e de gerenciamento. Isso é particularmente no caso de empresas familiares, como analisamos acima.

E esse ponto é crítico, pois quando o governo impõe um Monitor e este atesta que a empresa possui bom programa de conformidade e que não está praticando violações, o 
governo passa a ser, indiretamente, "fiador" da integridade da empresa. Assim, cometer uma violação, após um monitoramento adequado que atestou que a empresa possui bom programa de conformidade e controles internos efetivos, significa que o problema está na governança corporativa e, em última análise, nas pessoas e não nos mecanismos de integridade da empresa.

Outro problema que temos no Brasil surge com relação à autoridade governamental que poderá impor o Monitor e como resolver a questão do potencial conflito de competências entre, por exemplo, CGU, MPF, CADE, CVM, etc. Parece-nos claro, desde já, que a nomeação de múltiplos Monitores, com escopos distintos, seria inadequada.

Sobre o tema:

Um mesmo ato de corrupção, praticado para encobrir cartel e com fraude à licitação, pode ser sancionado com multas aplicadas na esfera administrativa pura pelo Tribunal de Contas da União, pelo Conselho Administrativo de Defesa Econômica, pela Controladoria-Geral da União, pelo órgão da Administração Pública com base na Lei de Licitações, pela Administração Tributária para aplicar multa sobre tributos devidos (segundo o princípio "non olet"), assim como pode ser penalizado de modo independente na esfera administrativa-judicial, com um controle dotado de absoluta independência que não pode ser preterido dadas as garantias que revestem a função jurisdicional e o caráter autônomo e constitucional dessa esfera de responsabilização ${ }^{355}$.

Nota-se, assim, que dúvidas não faltam e ainda precisamos passar por um período de reflexão e ajuste para que a utilização de Monitores seja mais compatível e adequada no Brasil. Não nos resta outra opção além de seguir acompanhando a discussão de forma atenta, na esperança de que os Monitores, quando utilizados, sejam efetivos e o menos custoso possível para as empresas.

Feitos esses esclarecimentos, as principais conclusões dessa pesquisa são as seguintes:

1) Existe uma série de normas que regulam o tema de acordos no âmbito judicial e administrativo que são relevantes para que a nomeação de Monitores seja compatível com o ordenamento jurídico pátrio;

355 Nota Técnica n. ${ }^{\circ}$ 1/2017 - 5a Câmara de Coordenação e Revisão (Combate à Corrupção), do MPF, p. 15. Disponível em: http://www.mpf.mp.br/atuacao-tematica/ccr5/notas-tecnicas/docs/nt-01-2017-5ccr-acordo-deleniencia-comissao-leniencia.pdf. Acesso em 11 de julho de 2020. 
2) Programas de conformidade devem ser customizados e efetivos. Conformidade deve ser visto como meio, e não um fim em si mesmo. Custos com a implementação do monitoramento, do programa de conformidade e os problemas gerados para o negócio devem ser levados em conta para que se evitem excessos gerados pela "onda" da conformidade. Isso não significa, de forma alguma, que conformidade não é importante, mas apenas que os Monitores não devem ser impostos em todos os casos e sem maiores ponderações;

3) A adoção de Monitores pode, em determinados casos, ser uma forma e eficiente de reduzir a corrupção e práticas anticompetitivas no ambiente empresarial;

4) A sofisticação e o rigor dos Monitores adotados nos EUA produzem significativos avanços nos sistemas de conformidade e controles internos das empresas, de modo que pode ser uma importante referência para que empresas brasileiras possam seguir e, assim, implementar medidas que atendam às exigências das autoridades de diferentes países ao mesmo tempo (i.e., um programa que seja considerado bom no Brasil e no exterior). Nada obstante, a imposição do Monitor deve ser amplamente justificada e a sua atuação deve estar relacionada com violações concretas à legislação anticorrupção (ou seja, as autoridades não devem possuir um "cheque em branco" para definir o que incluir em um acordo ou decisão); 


\section{BIBLIOGRAFIA}

ALA'J. Padideh. The Legacy of Geographical Morality and Colonialism: A Historical Assessment of the Current Crusade Against Corruption. Vanderbilt Journal of Transitional Law, Vol. 33, n. ${ }^{\circ}$, October, 2000.

ALDRIGHI, D. M. Risks of Wrongdoing in Public Companies and Ways to Cope with Them: The Case of Brazil. In International Handbook on the Economics of Corruption. v. 2, 2011.

ALENCAR, Paulo Wunder de. A lei anticorrupção é "só para inglês ver? Uma breve análise comparativa entre os sistemas brasileiro e norte-americano de combate à corrupção. Revista

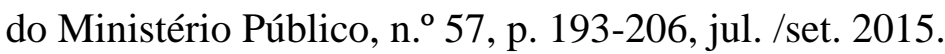

ALEXANDRE, Ricardo; DEUS, João de. Direito Administrativo Esquematizado. $1^{\text {a }}$ ed. São Paulo: Editora Método, 2015.

ARAS, Vladimir. Acordos penais no Brasil: uma análise à luz do direito comparado. In CUNHA, Rogério Sanches; BARROS, Francisco Dirceu; SOUZA, Renne do Ó; CABRAL, Rodrigo Leite Ferreira. Acordo de não persecução penal - Resolução 181/2017 do CNMP, 336 p., vários autores - Salvador: Juspodivm, 2017.

BERTONCINI, Mateus. "Do acordo de leniência - comentários aos artigos 16 e 17 da Lei Anticorrupção. In "Lei Anticorrupção: comentários à Lei n. o 12846/2013”. Coordenação: Eduardo Cambi e Fábio André Guaragni. Org.: Mateus Bertoncini. $1^{\mathrm{a}}$ ed. - S. Paulo: Almedina, 2014.

BRONITT, S., D’AMICO, A.. Fighting Cartels and Corporate Corruption - Public Versus Private Enforcement Models: A False Dichotomy? (Special Issue on Laura Guttuso's PublicPrivate Competition Law Enforcement Model). University of Queensland Law Journal, 37(1), 69, 2018.

CAPELA, Fábio. Plea bargaining: o projeto de "negociata penal" de Sérgio Moro: Revista: Justificando mentes inquietas pensam Direito, Disponível em: http://www.justificando.com/2019/05/29/plea-bargaining-o-projeto-de-negociata-penal-de-

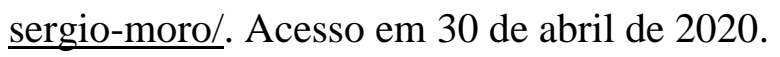


CARVAlHO, André Castro; BERTOCCELli, Rodrigo de Pinho; ALVIM, Tiago Cripa; VENTURINI, Otavio (Coord.). Manual de compliance. Rio de Janeiro: Forense, 2019.

CAVALHEIRO, Lucas Plea bargain: o que é isto, como é aplicado e como o ordenamento jurídico brasileiro pode implementá-lo? Revista Jus Navigandi. Disponível em: https://jus.com.br/artigos/72872. Acesso em 30 de abril de 2020.

COSTA JÚNIOR, Paulo José; PAGLIARO, Antônio. Dos crimes contra a Administração Pública. São Paulo: Malheiros, 1999.

COUTINHO, Diogo R. et al. (Coords.). Direito Econômico Atual. São Paulo: Editora Método, 2015 .

CRIMINAL DIVISION OF THE U.S. DEPARTMENT OF JUSTICE AND THE ENFORCEMENT DIVISION OF THE U.S. SECURITIES AND EXCHANGE COMMISSION, A Resource Guide to the Foreign Corrupt Practices Act, 2020. Disponível em: https://www.justice.gov/criminal-fraud/file/1292051/download Acesso em 11 de julho de 2020.

CRIMINAL DIVISION OF THE U.S. DEPARTMENT OF JUSTICE, Opinion Procedure Release 14-02, Nov. 7, 2014. Disponível em: http://www.justice.gov/sites/default/files/criminalfraud/legacy/2014/11/14/14-02.pdf.

Acesso em 11 de julho de 2020.

CUEVA, Ricardo Villas Bôas; FRAZÃO, Ana (Coord.). Compliance: perspectivas e desafios dos programas de conformidade. Belo Horizonte: Fórum, 2018.

DAVIS.Kevin E.. Between Impunity and Imperialism: The Regulation of Transnational Bribery. Pages 34 to 40 (selected pages from the chapter "The Birth of Modern Transnational Bribery Law” Oxford University Press, 2019.

DE LUCCA, Newton. A Corrupção da Lei. A misericórdia também corrompe? Estado de Direito. Disponível em: http://estadodedireito.com.br/a-corrupcao-da-lei-a-misericordiatambem-corrompe/. Acesso em 11 de julho de 2020.

DE LUCCA, Newton. Da ética geral à ética empresarial. São Paulo: Quartier Latin, 2009. 
DE LUCCA, Newton. Marco Civil da Internet - uma Visão Panorâmica dos Principais Aspectos Relativos às suas Disposições Preliminares. In Newton De Lucca; Adalberto Simão Filho; Cíntia Rosa Pereira de Lima. (Org.). Direito \& Internet III - Tomo I: Marco Civil da internet (Lei n. ${ }^{\circ}$ 12.965/2014). São Paulo: Quartier Latin, 2015.

ENCINAR DEL POZO, Miguel Ángel. El delito de corrupción privada en el Ámbito de los negocios. Cizur Menor: Editorial Aranzadi, 2016.

FAORO, Raymundo. Os donos do poder: formação do patronato político brasileiro. $3^{\mathrm{a}}$ ed., São Paulo: Globo, 2001.

FELL. A. London; WATSON. Alan. The Evolution of Law. Baltimore: Johns Hopkins University Press, 1985.

FISMAN. Ray. GOLDEN. Miriam A. Corruption: What Everyone Needs to Know. Oxford University Press, 2017.

FISS, Owen. Against settlement. 93 Yale L.J. 1073, 1984.

FORD, C., HESS, D.. Can corporate Monitorships improve corporate compliance? The Journal of Corporation Law, 34(3), 679, 2009.

FORD, C., HESS, D.. Corporate Monitorships and New Governance Regulation: In Theory, in Practice, and in Context. Law \& Policy, 33(4), 509-541, 2011.

FORGIONI, Paula A. Os Fundamentos do Antitruste. 10. ed. São Paulo: Editora Revista dos Tribunais, 2018.

GIACOMOLLI, Nereu José. Legalidade, oportunidade e consenso no Processo Penal na perspectiva das garantias constitucionais: Alemanha, Espanha, Itália, Portugal, Brasil. Porto Alegre: Livraria do Advogado, 2006.

GLOBAL INVESTIGATION REVIEW. The Guide To Monitorships. Editors. Anthony S Barkow, Neil M Barofsky and Thomas J Perrelli. Law Business Research Ltd., 2019. 
GOMES, Luiz Flávio. Princípio da não auto-incriminação: significado, conteúdo, base jurídica e âmbito de incidência. Disponível em: http://www.lfg.com.br. Acesso em 11 de julho de 2020 .

GRANOVETTER, M.. The Social Construction of Corruption. In On Capitalism. Stanford University Press, 2007.

GRAU, Eros. A ordem econômica na Constituição de 1998, 18ª Ed., São Paulo: Malheiros, 2017.

GRAU. Eros Roberto. Por que tenho medo dos juízes: (a intepretação/aplicação do direito e os princípios). $7^{\mathrm{a}}$ edição. São Paulo: Malheiros, 2016.

HANEY. Brian S. Calculating Corporate Compliance \& The Foreign Corrupt Practices Act. 19 Pittsburgh Journal of Technology Law \& Policy, 2018-2019.

HERRMANN. Joachim. Bargaining Justice - A Bargain for German Criminal Justice?, 53 U. Pitt. L. Rev., 1992.

ISSACHAROFF, Samuel; KLONOFF, Robert H. The public value of settlement. 78 Fordham Law Review 1177, 2009-2010.

JACOBS, Laverne. SASHA. Baglay. KWOK. Melissa. MAVRIKKOU, Maria. TAY. Ki, The Nature of Inquisitorial Processes in Administrative Regimes: Global Perspectives Research Workshop Report (November 1, 2011). Canadian Journal of Administrative Law and Practice, Vol. 24, pp. 261-283, 2011.

LANGBEIN. John H. Land without Plea Bargaining: How the Germans Do It. Michigan Law Review. Vol. 78, No. 2 (Dec., 1979), pp. 204-225.

LANGER. Máximo. From Legal Transplants to Legal Translations: The Globalization of Plea Bargaining and The Americanization Thesis in Criminal Procedure. Harvard International Law Journal. Vol. 45. n. ${ }^{\circ}$ 1, Winter 2004.

LEFF. Nathaniel. Economic Development Through Bureaucratic Corruption. American Behavioral Scientist. Nov., 1964. 
LOPES JR, Aury. Fundamentos do processo penal: introdução crítica. $2^{a}$ ed. São Paulo: Saraiva, 2016.

LUZ, Yuri Corrêa da. Entre bens jurídicos e deveres normativos: um estudo sobre os fundamentos do Direito Penal contemporâneo. $1^{\text {a }}$ ed. São Paulo: IBCCRIM, 2013.

MEIRELLES, Hely Lopes. Direito Administrativo brasileiro. $43^{a}$ ed. São Paulo: Malheiros, 2018.

MELLO, Celso Antonio Bandeira de. Curso de Direito Administrativo. 34 a ed. São Paulo: Malheiros, 2019.

MEMORANDUM FROM BRIAN A. BENCZKOWSKI, Assistant Attorney General, U.S. Dep't of Justice, to All Criminal Division Personnel, Selection of Monitors in Criminal Division Matters (Oct. 11, 2018) (“Benczkowski Memo”). Disponível em: https://www.justice.gov/criminal-fraud/file/1100366/download. Acesso em 11 de julho de 2020.

MIRABETE, Julio Fabbrini. Processo Penal. 2a ed. São Paulo: Atlas, 1993.

NUCCI, Guilherme de Souza. Código Penal Comentado. $8^{a}$ ed. São Paulo: Revista dos Tribunais, 2008.

OCDE. Convenção sobre o Combate da Corrupção de Funcionários Públicos Estrangeiros em Transações Comerciais Internacionais. Disponível em: http://www.planalto.gov.br/ccivil_03/decreto/D3678.htm. Acesso em 11 de julho de 2020.

OEA. Convenção interamericana sobre a corrupção. Disponível em: http://www.oas.org/juridico/portuguese/treaties/b-58.htm. Acesso em 11 de julho de 2020.

OLIVEIRA, Eugênio Pacelli de. Curso de Processo Penal. 11ª ed. Rio de Janeiro: Lumen Juris, 2009.

OLIVEIRA, Gesner; RODAS, João Grandino. Direito e economia da concorrência. São Paulo: Renovar, 2004.

OLIVEIRA, Gustavo Henrique Justino de. A insegurança jurídica das empresas e os acordos 
de leniência. Conjur. 29 de maio de 2017. Disponível em: https://www.migalhas.com.br/depeso/259553/a-inseguranca-juridica-das-empresas-e-osacordos-de-leniencia-na-legislacao-anticorrupcao-brasileira. Acesso em 11 de julho de 2020.

ONU. Convenção das Nações Unidas contra a Corrupção. Disponível em: http://www.unodc.org/lpo-brazil/pt/corrupcao/convencao.html. Acesso em 11 de julho de 2020.

PARGENDLER, Mariana. O direito contratual comparado em nova perspectiva: revisitando as diferenças entre os sistemas romano-germânico e de common law. In. Revista Direito GV. V. 13. n. ${ }^{\circ}$ 3. set/dez., 2017.

PEIXOTO, Geovane de Mori. A adoção de sistema de compliance e o novo marco legal de combate à corrupção. Revista Síntese: direito empresarial, v. 8, n. 43, mar./abr., 2015.

PINHO, Humberto Dalla Bernardina de; PAUMGARTTEN, Michele. O acesso à Justiça e o uso da mediação na resolução dos conflitos submetidos ao Poder Judiciário. Boletim Informativo Juruá. vol. 1. p. 11-14, 2013.

PRADO, Luiz Regis. Curso de Direito Penal Brasileiro. $16^{\mathrm{a}}$ ed. São Paulo: Revista dos Tribunais, v. 3, 2018.

PRADO, Luiz Regis. Delito licitatório e bem jurídico-penal: algumas observações. Revista dos Tribunais. vol.957, julho 2015.

PRADO, Luiz Regis. Tratado de Direito Penal brasileiro, São Paulo: Revista dos Tribunais, 2017.

REALE, Miguel. Lições Preliminares de Direito, São Paulo: José Bushatsky, 1974.

ROSE-ACKERMAN, Susan., \& Palifka, Bonnie J.. Corruption and Government: Causes, Consequences, and Reform. Cambridge: Cambridge University Press, 2016.

SALOMÃO FILHO, Calixto. Direito concorrencial. São Paulo: Malheiros, 2013. SANCTIS, Fausto Martins. In Código Penal Comentado, organizado por GRECO FILHO, Vicente; JALIL, Maurício Schaun Barueri: Manole, 2016. 
SANCHEZ BADIN. Michelle R. SANCHEZ BADIN. Arthur. Anticorruption in Brazil: From Transnational Legal Order to Disorder. Part of: New Directions in Anticorruption Law. AJIL Unbound. Published online by Cambridge University Press: 14 October, 2019.

SILVA SANCHEZ, José Maria. A expansão do Direito Penal. São Paulo: Revista dos Tribunais, 2002.

STEINER. George. After Babel: Aspects of Language and Translation 266, 3ª ed., 1998.

STEVENSON, Drury D. and Wagoner, Nicholas J., FCPA Sanctions: Too Big to Debar? Fordham Law Review, Vol. 80, p. 775. November 1, 2011. Disponível em: http://ssrn.com/abstract=1811126. Acesso em 11 de julho de 2020.

SWENSON. Thomas. The German "Plea Bargaining” Debate, 7 Pace Int'1 L Rev. 373, 1995.

TOURINHO FILHO, Fernando da Costa. Manual de processo penal. $11^{\mathrm{a}}$ ed. rev. e atual. São Paulo: Saraiva, 2009.

U.S SECURITIES AND EXCHANGE COMMISSION, 2014 Annual Report to Congress on the Dodd-Frank Whistleblower Program. Disponível em: http://www.sec.gov/about/offices/owb/annual-report-2014.pdf. Acesso em 11 de julho de 2020.

UNITED STATES DISTRICT COURT, EASTERN DISTRICT OF NEW YORK. 2012. United States of America v. Garth Peterson Winer, Kenneth. Husisian, Gregory. The 'Knowledge' Requirement of the FCPA Anti Bribery Provisions: Effectuating or Frustrating Congressional Intent?, White Collar Crime, October 2009. Disponível em: http://www.foley.com/files/Publication/a1d4aa39-1324-4018-bd8acbddfc15e02/Presentation/PublicationAttachment/7e8b814e-446b-411d-87221e747b29b303/FCPAWinerHusisian2009.pdf. Acesso em 11 de julho de 2020.

UNITED STATES OF AMERICA V. ALSTOM S.A. - Plea Agreement, Disponível em: http://www.justice.gov/sites/default/files/opa/pressreleases/attachments/2014/12/22/alstom sa_plea_agreement.pdf. Acesso em 11 de julho de 2020.

US ATTORNEYS OFFICE. Criminal Resource Manual 166. Morford Memorandum. 
Selection and Use of Monitors in Deferred Prosecution Agreements and Non-Prosecution Agreements with Corporations. March 7, 2008.

US ATTORNEYS. Criminal Resource Manual. Grindler Memorandum, Additional Guidance on the Use of Monitors in Deferred Prosecution Agreements and Non-Prosecution Agreements with Corporations, May 25, 2010.

VAN ALSTINE, Michael P, 2012. Treaty Double Jeopardy: The OECD Anti-Bribery Convention and the FCPA. Ohio State Law Journal, Vol. 73. Disponível em: http://ssrn.com/abstract=2202177. Acesso em 11 de julho de 2020.

VERÍSSIMO. Carla. Compliance: incentivo à adoção de medidas anticorrupção. São Paulo, SaraivaJur, 2018.

VOLOSIN. Natalia A. Argentina's Corruption Machine: Towards an Institutional Approach. Corruption in Latin America: How Politicians and Corporations Steal from Citizens, edited by Robert I. Rotberg, 2019. 


\section{ANEXO I - DISPOSITIVOS USADOS COMO BASE JURÍDICA PARA O ACORDO MPF E ODEBRECHT}

\begin{tabular}{|c|c|}
\hline Norma & Texto \\
\hline $\begin{array}{l}\text { Art. } 129 \text {, inc. I, da } \\
\text { Constituição Federal }\end{array}$ & $\begin{array}{l}\text { Art. 129. São funções institucionais do Ministério Público: I - promover, } \\
\text { privativamente, a ação penal pública, na forma da lei. }\end{array}$ \\
\hline $\begin{array}{l}\text { Arts. } 13 \text { a } 15 \text { da Lei n. }{ }^{\circ} \text {. } \\
9.807 / 99\end{array}$ & $\begin{array}{l}\text { Art. 13. Poderá o juiz, de ofício ou a requerimento das partes, conceder o perdão } \\
\text { judicial e a consequente extinção da punibilidade ao acusado que, sendo primário, } \\
\text { tenha colaborado efetiva e voluntariamente com a investigação e o processo } \\
\text { criminal, desde que dessa colaboração tenha resultado: } \\
\text { I - a identificação dos demais co-autores ou partícipes da ação criminosa; } \\
\text { II - a localização da vítima com a sua integridade física preservada; III - a } \\
\text { recuperação total ou parcial do produto do crime. Parágrafo único. A concessão do } \\
\text { perdão judicial levará em conta a personalidade do beneficiado e a natureza, } \\
\text { circunstâncias, gravidade e repercussão social do fato criminoso. } \\
\text { Art. 14. O indiciado ou acusado que colaborar voluntariamente com a investigação } \\
\text { policial e o processo criminal na identificação dos demais co-autores ou partícipes } \\
\text { do crime, na localização da vítima com vida e na recuperação total ou parcial do } \\
\text { produto do crime, no caso de condenação, terá pena reduzida de um a dois terços. } \\
\text { Art. 15. Serão aplicadas em benefício do colaborador, na prisão ou fora dela, } \\
\text { amedidas especiais de segurança e proteção a sua integridade física, considerando }\end{array}$ \\
\hline $\begin{array}{l}\text { Art. } 1^{\circ}, \S 5^{\circ} \text {, da Lei n. } \\
9.613 / 98\end{array}$ & $\begin{array}{l}\text { Art. 1º Ocultar ou dissimular a natureza, origem, localização, disposição, } \\
\text { movimentação ou propriedade de bens, direitos ou valores provenientes, direta ou } \\
\text { indiretamente, de infração penal. } \\
\text { (...) } \\
\text { §5o A pena poderá ser reduzida de um a dois terços e ser cumprida em regime aberto } \\
\text { ou semiaberto, facultando-se ao juiz deixar de aplicá-la ou substituí-la, a qualquer } \\
\text { tempo, por pena restritiva de direitos, se o autor, coautor ou partícipe colaborar } \\
\text { espontaneamente com as autoridades, prestando esclarecimentos que conduzam à } \\
\text { apuração das infrações penais, à identificação dos autores, coautores e partícipes, } \\
\text { ou à localização dos bens, direitos ou valores objeto do crime. }\end{array}$ \\
\hline
\end{tabular}




\begin{tabular}{|c|c|}
\hline $\begin{array}{l}\text { Art. } 5^{\circ}, \S 6^{\circ} \text {, da Lei n. } \\
7.347 / 85\end{array}$ & $\begin{array}{l}\text { (...) } \\
\S 6^{\circ} \text { Os órgãos públicos legitimados poderão tomar dos interessados compromisso } \\
\text { de ajustamento de sua conduta às exigências legais, mediante cominações, que terá } \\
\text { eficácia de título executivo extrajudicial. }\end{array}$ \\
\hline $\begin{array}{l}\text { Art. } 26 \text { da Convenção } \\
\text { de Palermo }\end{array}$ & 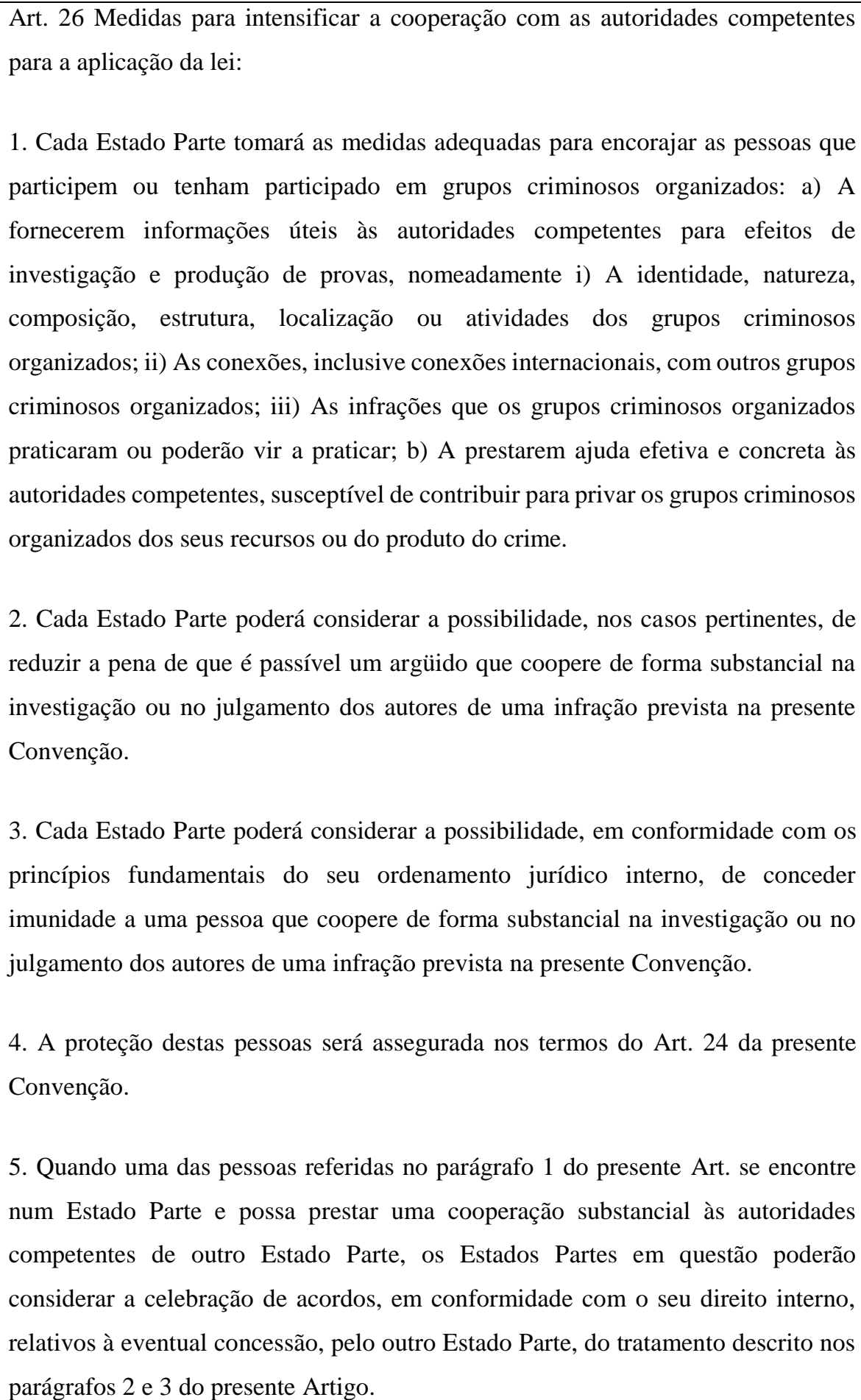 \\
\hline
\end{tabular}




\begin{tabular}{|c|c|}
\hline $\begin{array}{l}\text { Art. } 37 \text { da Con } \\
\text { de Mérida }\end{array}$ & $\begin{array}{l}\text { Art. 37. Cooperação com as autoridades encarregadas de fazer cumprir a lei } \\
\text { 1. Cada Estado Parte adotará as medidas apropriadas para restabelecer as pessoas } \\
\text { que participem ou que tenham participado na prática dos delitos qualificados de } \\
\text { acordo com a presente Convenção que proporcionem às autoridades competentes } \\
\text { informação útil com fins investigativos e probatórios e as que lhes prestem ajuda } \\
\text { efetiva e concreta que possa contribuir a privar os criminosos do produto do delito, } \\
\text { assim como recuperar esse produto. } \\
\text { 2. Cada Estado Parte considerará a possibilidade de prever, em casos apropriados, } \\
\text { a mitigação de pena de toda pessoa acusada que preste cooperação substancial à } \\
\text { investigação ou ao indiciamento dos delitos qualificados de acordo com a presente } \\
\text { Convenção. } \\
\text { 3. Cada Estado parte considerará a possibilidade de prever, em conformidade com } \\
\text { os princípios fundamentais de sua legislação interna, a concessão de imunidade } \\
\text { judicial a toda pessoa que preste cooperação substancial na investigação ou no } \\
\text { indiciamento dos delitos qualificados de acordo com a presente Convenção. } \\
\text { 4. A proteção dessas pessoas será, mutatis mutandis, a prevista no Art. } 32 \text { da } \\
\text { presente Convenção. } \\
\text { 5. Quando as pessoas mencionadas no parágrafo } 1 \text { do presente Art. se encontrem } \\
\text { em um Estado Parte e possam prestar cooperação substancial às autoridades } \\
\text { competentes de outro Estado Parte, os Estados Partes interessados poderão } \\
\text { considerar a possibilidade de celebrar acordos ou tratados, em conformidade com } \\
\text { trato previsto nos parágrafos } 2 \text { e } 3 \text { do presente Artigo. }\end{array}$ \\
\hline $\begin{array}{l}\text { Arts. } 4^{\circ} \text { a } 8^{\circ} \text { da Lei no } \\
12.850 / 2013\end{array}$ & $\begin{array}{l}\text { Art. } 4^{\circ} \mathrm{O} \text { juiz poderá, a requerimento das partes, conceder o perdão judicial, reduzir } \\
\text { em até } 2 / 3 \text { (dois terços) a pena privativa de liberdade ou substituí-la por restritiva } \\
\text { de direitos daquele que tenha colaborado efetiva e voluntariamente com a } \\
\text { investigação e com o processo criminal, desde que dessa colaboração advenha um } \\
\text { ou mais dos seguintes resultados: } \\
\text { I - a identificação dos demais coautores e partícipes da organização criminosa e das } \\
\text { infrações penais por eles praticadas; } \\
\text { II - a revelação da estrutura hierárquica e da divisão de tarefas da organização } \\
\text { criminosa; }\end{array}$ \\
\hline
\end{tabular}




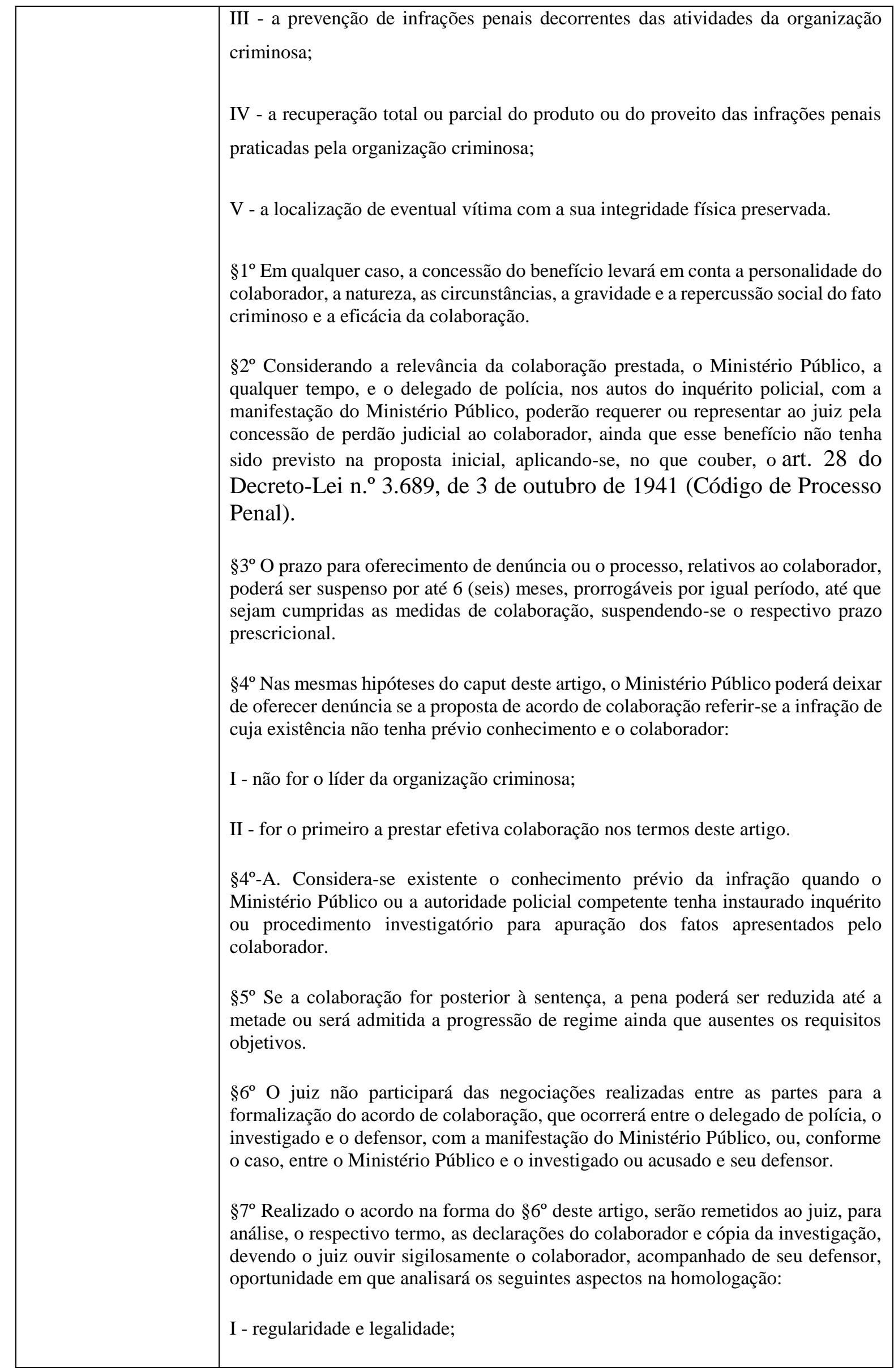




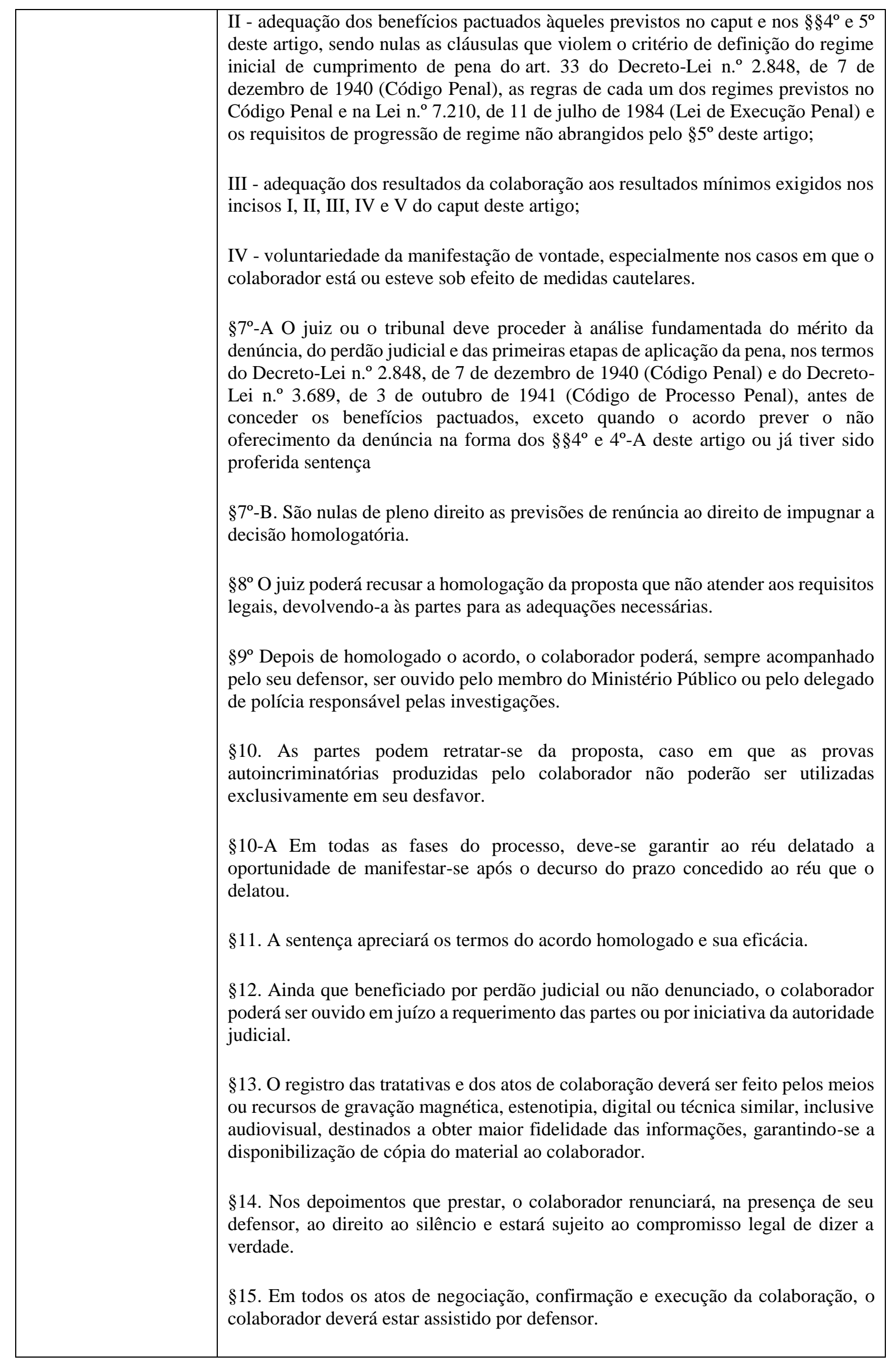




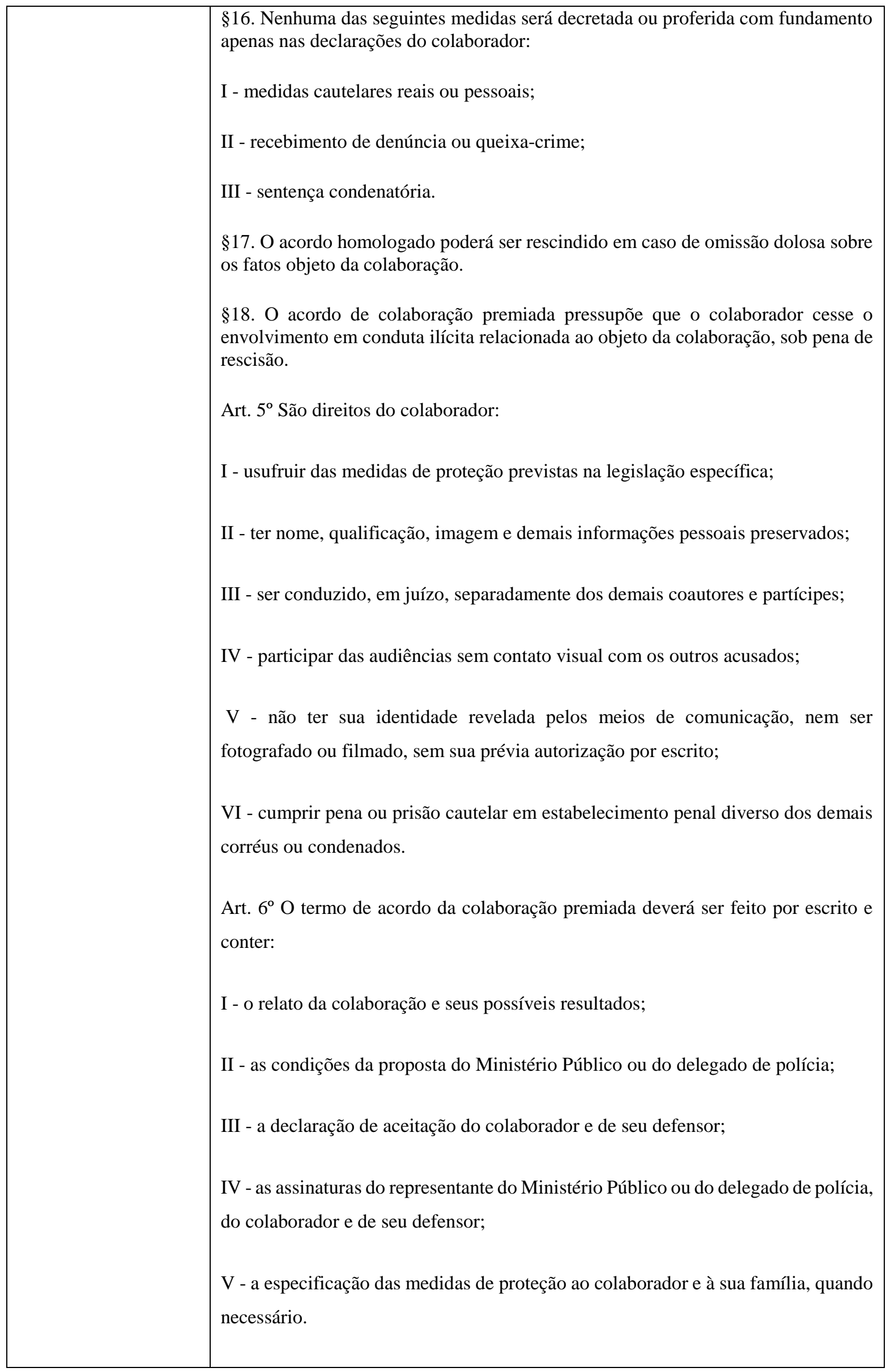




\begin{tabular}{|c|c|}
\hline & 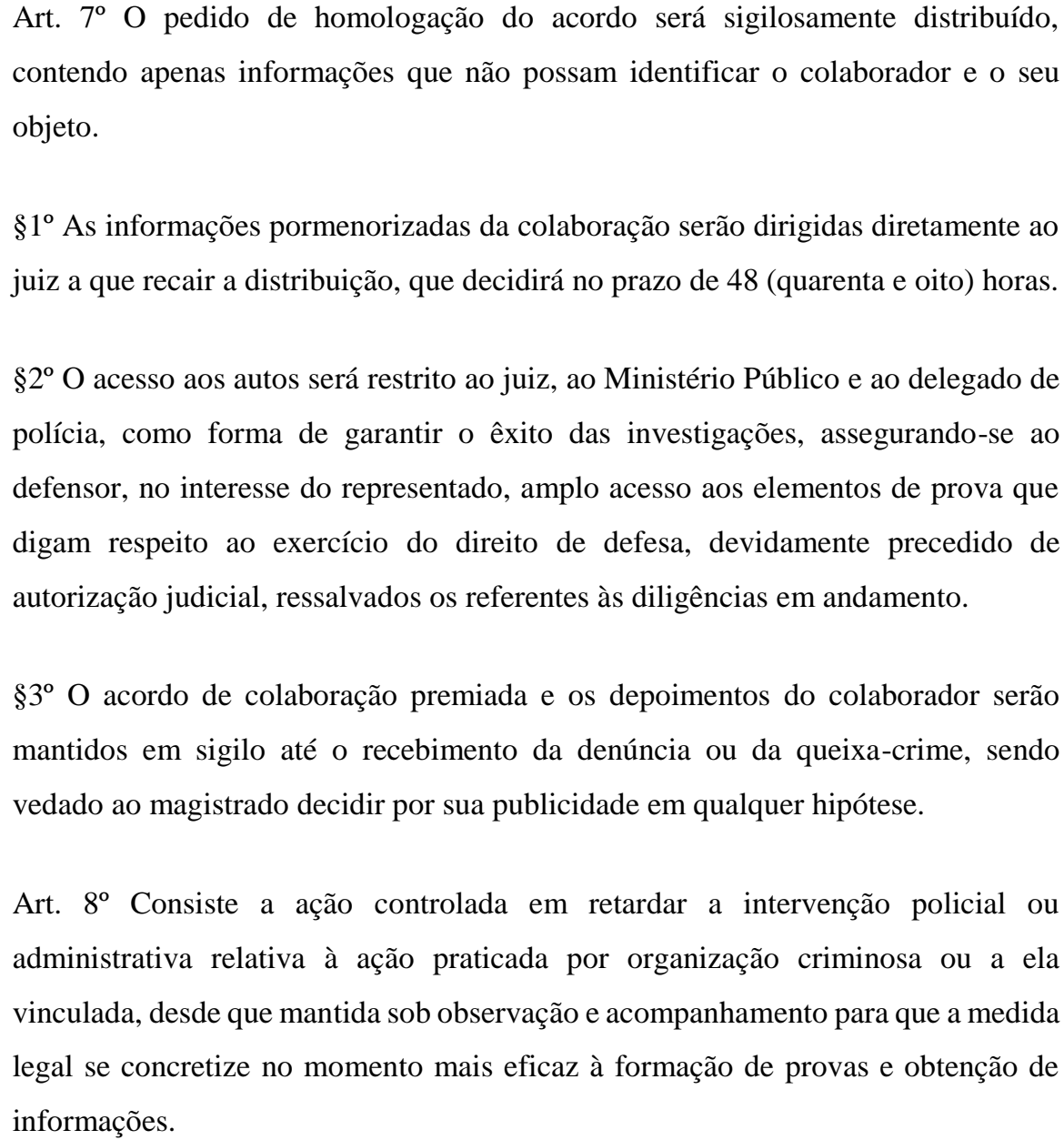 \\
\hline $\begin{array}{l}\text { Arts. } 3^{\circ}, \S 2^{\circ} \text { e } \$ 3^{\circ}, \\
485, \text { VI e } 487, \text { III, "b" } \\
\text { e "c", do CPC }\end{array}$ & 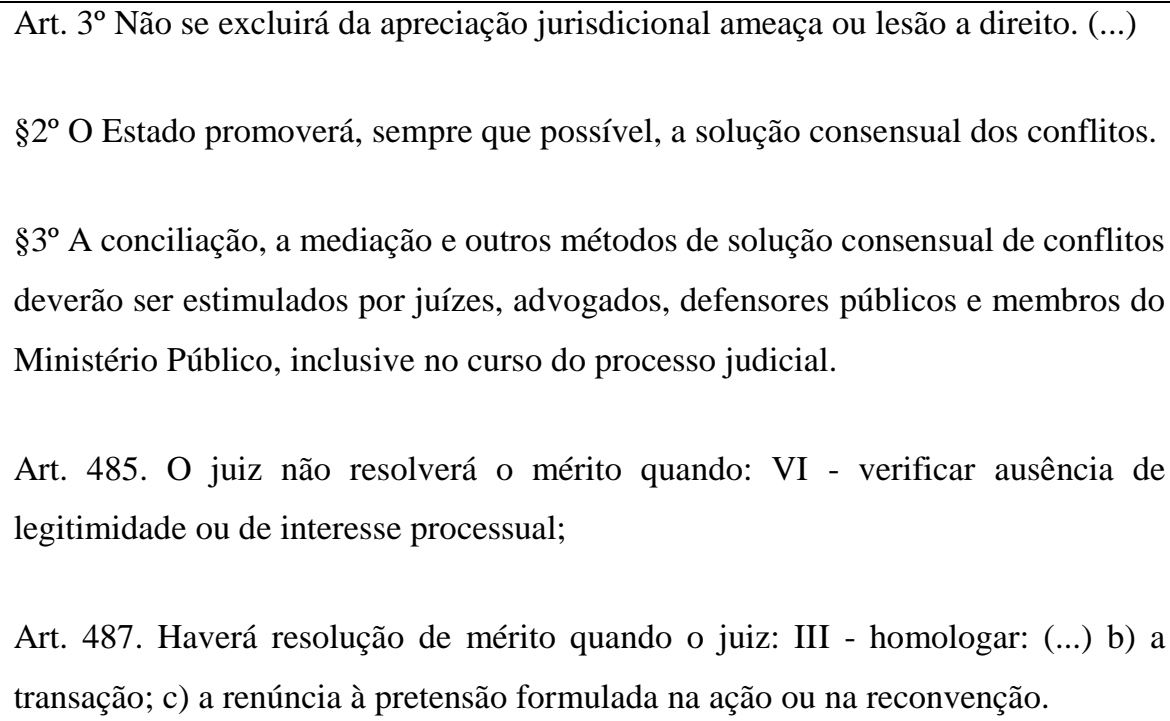 \\
\hline $\begin{array}{l}\text { Arts. } 840 \text { e 932, III, do } \\
\text { Código Civil }\end{array}$ & $\begin{array}{l}\text { Art. 840. É lícito aos interessados prevenirem ou terminarem o litígio mediante } \\
\text { concessões mútuas. } \\
\text { Art. 932. São também responsáveis pela reparação civil: }\end{array}$ \\
\hline
\end{tabular}




\begin{tabular}{|c|c|}
\hline & $\begin{array}{l}\text { III - o empregador ou comitente, por seus empregados, serviçais e prepostos, no } \\
\text { exercício do trabalho que lhes competir, ou em razão dele; }\end{array}$ \\
\hline $\begin{array}{l}\text { Arts. } 16 \text { a } 21 \text { da Lei no } \\
12.846 / 2013\end{array}$ & 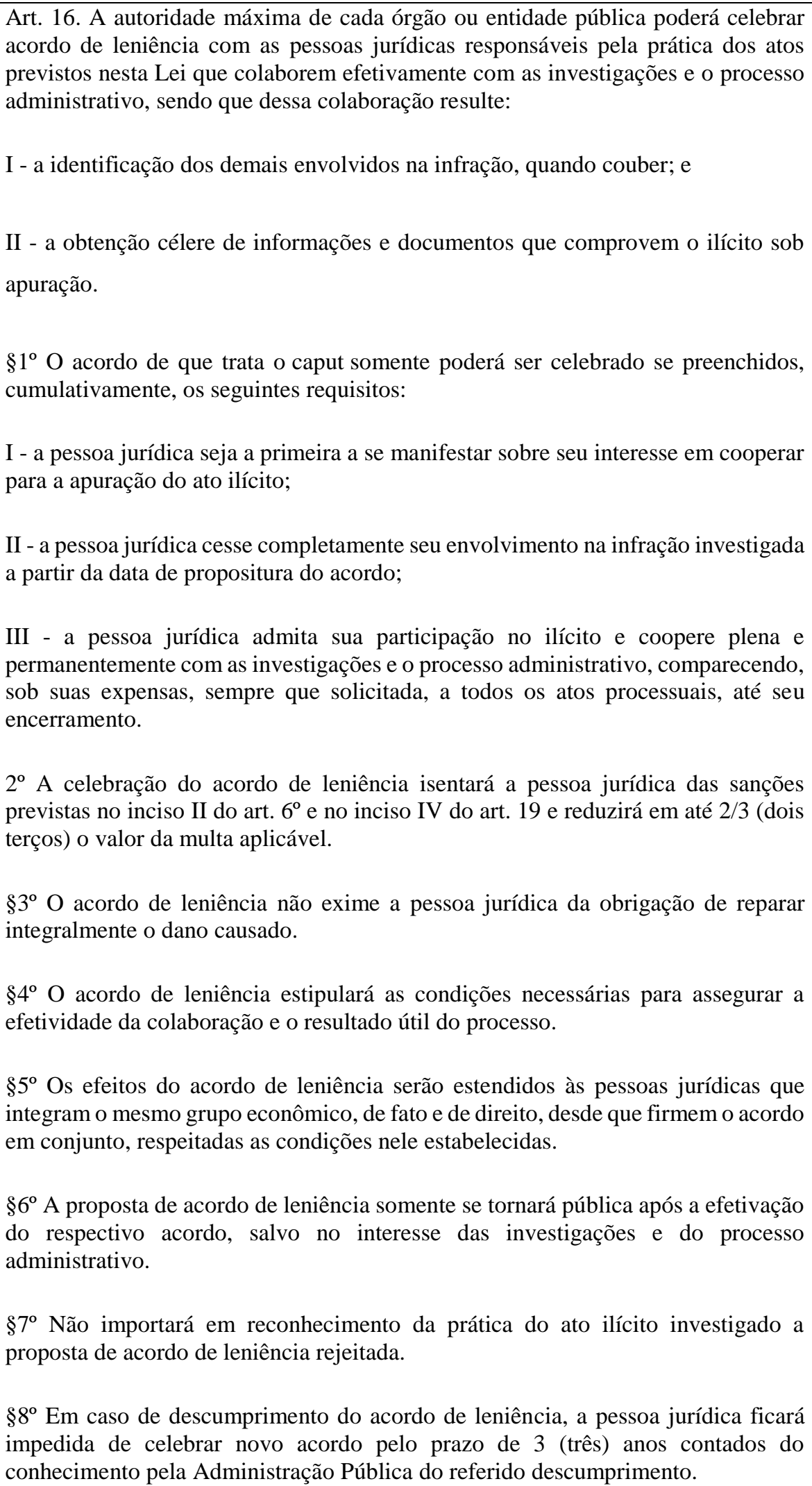 \\
\hline
\end{tabular}




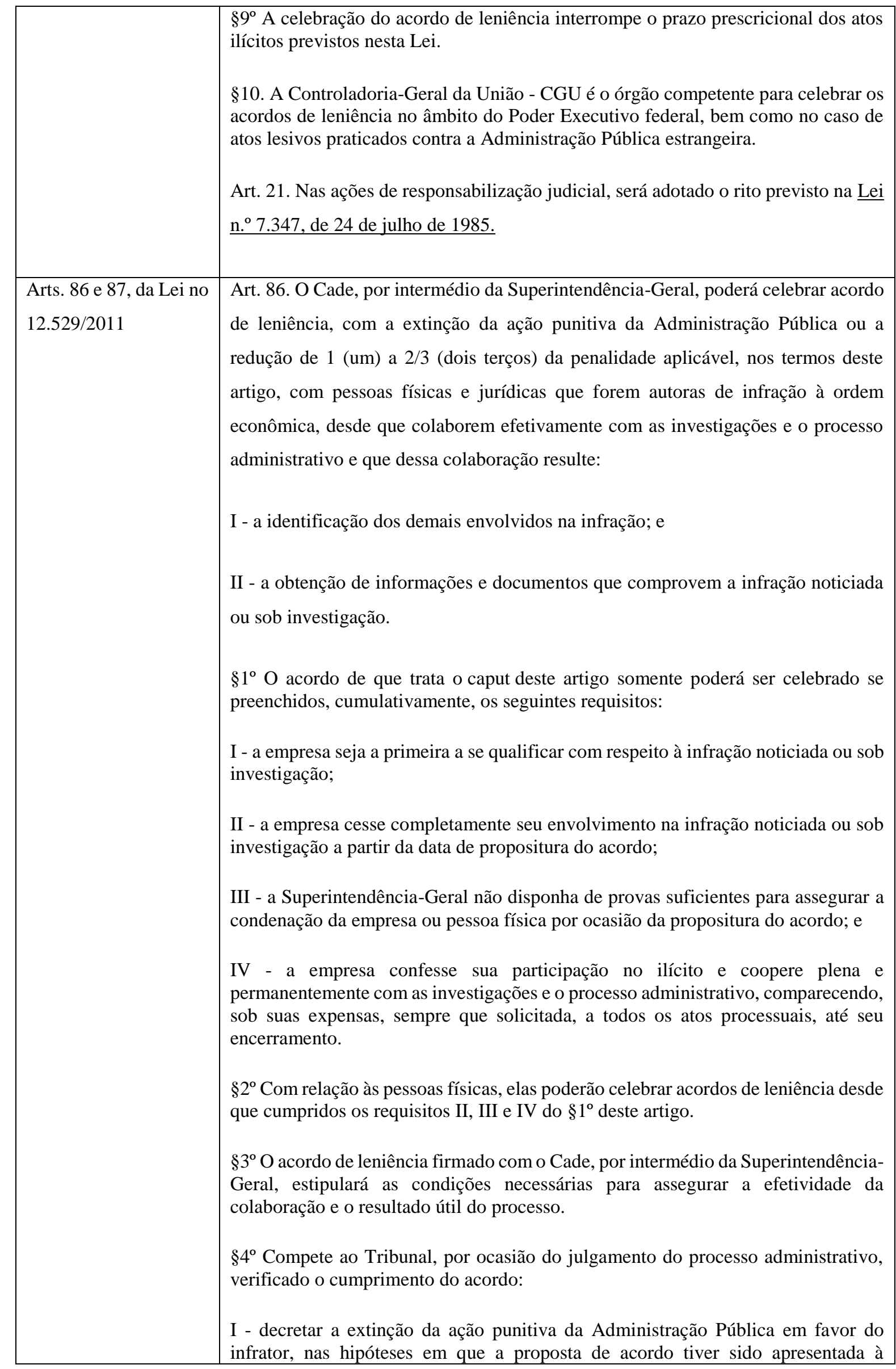




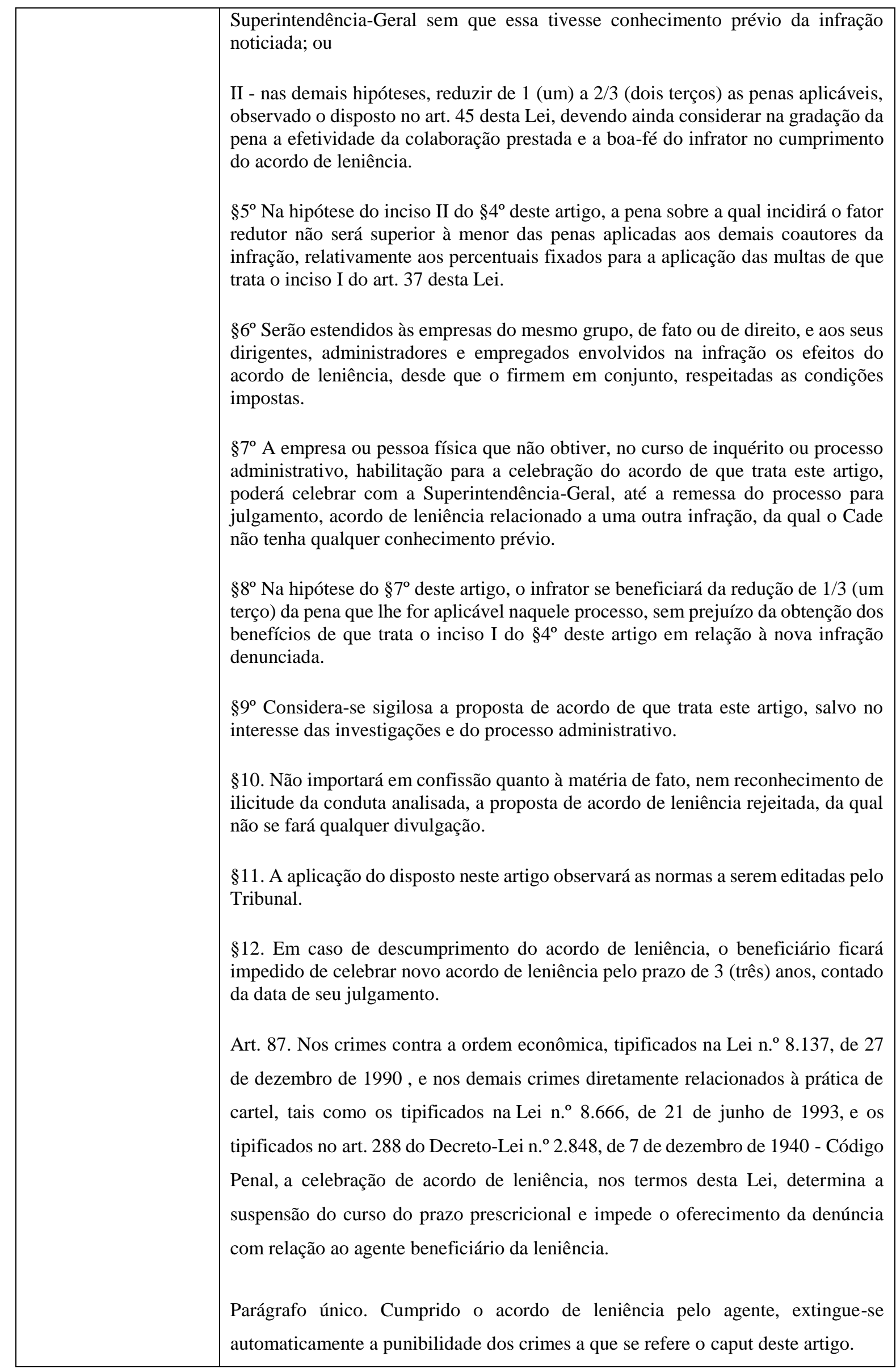




\begin{tabular}{|l|l|l|}
\hline $\begin{array}{l}\text { Art. } 2^{\circ} \text { da Lei } .^{\circ}{ }^{\circ} .140 / 2015 \\
\text { I - imparcialidade do mediador; }\end{array}$ & $\begin{array}{l}\text { II - isonomia entre as partes; } \\
\text { III - oralidade; } \\
\text { IV - informalidade; } \\
\text { V - autonomia da vontade das partes; } \\
\text { VI - busca do consenso; } \\
\text { VII - confidencialidade; } \\
\text { VIII - boa-fé. } \\
\S 1^{\circ} \text { Na hipótese de existir previsão contratual de cláusula de mediação, as partes } \\
\text { deverão comparecer à primeira reunião de mediação. } \\
\S 2^{\circ} \text { Ninguém será obrigado a permanecer em procedimento de mediação. }\end{array}$ \\
\end{tabular}

